DOE/ER/52159--3

DE92 006712

\title{
Neutral Transport and Helium Pumping of ITER
}

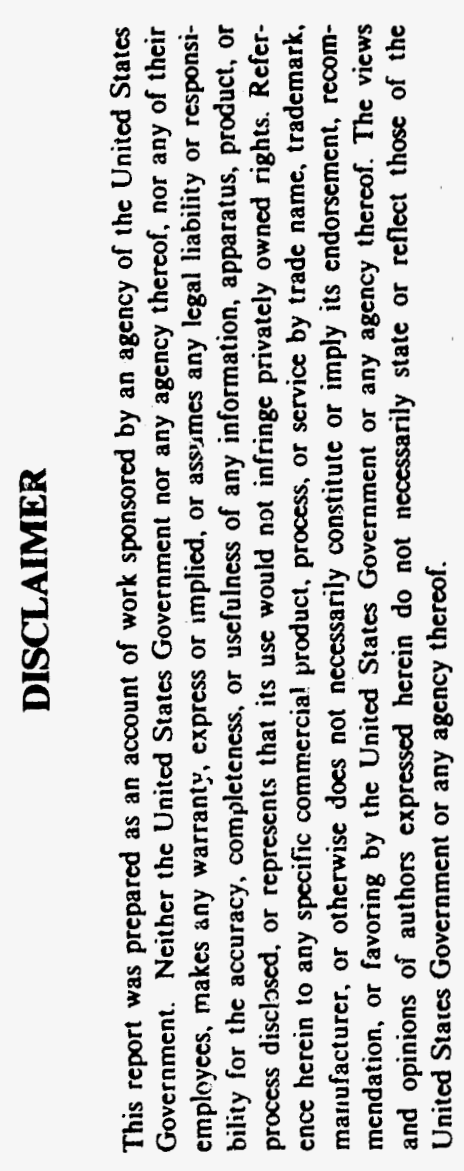

\author{
Annual Progress Report \\ for period January 15, i991 - January 14, 1992 \\ David N. Ruzic \\ University of Illinois \\ Urbana, Illinois 61801 \\ December 1991 \\ prepared for \\ The U.S. Department of Energy \\ Agreement No. DE-FG02-89ER52159
}

NOTICE

This report was prepared as an account of work sponsored by the United States Government. Neither the United States nor the Department of Energy, nor any of their employees, nor any of their contractors, subcontractors, or their employees, makes any warranty, expressed or implied, or assumes any legal liability or responsibility for the accuracy, completeness, or usefulness of any information, apparatus, product or process disclosed or represents that its use would not infringe privately-owned rights. 


\section{Abstract}

Following the success of the previous years work in modeling the divertor and pump duct of ITER, more 2-D variations of the geometry were introduced. These consisted of reducing the vertical height of the pump duct by $10 \%$ and $25 \%$. These changes were folded in to the other geometrical variables. Results show that $D / T$ recycling is basically uneffected by the reduced pump duct size. The He recycling is effected. Less helium is pumped as the pump duct is closed. The helium is still pumped more efficiently than the $D / T$, but the enhancement factor is reduced. Shifting the profile by $20 \mathrm{~cm}$ still produced more pumped helium, but this effect is also lessened as the duct is narrowed. 


\section{Introduction}

There were two tasks identified for this years work in the revised statement of work (Nov. 20, 1990 adderidum to "Neutral Transport \& Helium Pumping of ITER"). The first of these was to couple DEGAS to B2 in a more self-consistent manner. This type of task is one which stretches over many years. More work has been done in this area, but definitive results have not yet been produced. Rapid progress on this task requires significant efforts from individuals not supported by this contract. That effort was expected but not fully realized.

The second and final task was completed fully. More geometrical variations of the ITER pump duct geometry were performed. An example of those results are detailed in the following sections. 


\section{Results}

T..e height of the divertor pump duct was reduced by $10 \%$ and 25\% for the Physics base case ITER scenario. These two cases and two cases where the helium flux profile was shifted $+20 \mathrm{~cm}$ out along the divertor plate toward the duct were run The results are compared to the previous results. The format and definitions are the same as the last article published: (D.N. Ruzic, K.A. Werley, S.A. Cohen, J. Nucl. Mater., 176\&177 (1990) 926-934.) Tables are included on the next page.

The results show that $\mathrm{D} / \mathrm{T}$ recycling is basically uneffected by the reduced pump duct . The He recycling is effected. Less helium is pumped as the pump duct is closed. The helium is still pumped more efficiently than the $D / T$, but the enhancement factor is reduced. Shifting the profile by $20 \mathrm{~cm}$ still produced more pumped helium, but this effect is also lessened as the duct is narrowed. A narrowing of the duct by $10 \%$ reduces helium throughput from 83 exiting atoms per 1000 striking the plate to 79 exiting atoms, a $5 \%$ effect. Narrowing of the duct by $25 \%$ reduces the number of exiting He atoms from 83 per 1000 to 65 per 100 striking the plate---a 22\% effect. Keep in mind that many more flights are needed to increase the accuracy beyond the present $+/-11 \%$ on each of the raw exit quantities. 
Looking at the 3-D graphs one sees an asymmetry of higher densities at the top of the duct---the very place the duct is being reduced. Some of the 3-d graphs are included.showing the helium, and $\mathrm{D} / \mathrm{T}$ densities and the geometry. In each of the cases the albedo of the duct was kept constant at $12.5 \%$ transmission.

All geometries correspond to "big nose, reference lip"

\begin{tabular}{|c|c|c|c|c|c|}
\hline \multirow[b]{2}{*}{ base case } & \multicolumn{2}{|c|}{$\begin{array}{l}\text { Density in Duct } \\
(\mathrm{D} / \mathrm{T})_{2} \\
\qquad 10^{13} \mathrm{~cm}^{-3}\end{array}$} & \multirow{2}{*}{$\begin{array}{l}R_{d / t} \\
.969\end{array}$} & \multirow{2}{*}{$\begin{array}{l}R_{h e} \\
.917\end{array}$} & \multirow{2}{*}{$\begin{array}{l}F \\
2.67\end{array}$} \\
\hline & 2.86 & 0.95 & & & \\
\hline $10 \%$ red. & 3.37 & 1.02 & .970 & .921 & 2.63 \\
\hline $25 \%$ red. & 2.85 & 0.70 & .969 & .935 & 2.10 \\
\hline $\begin{array}{l}\text { helium shifted } \\
\text { base case }\end{array}$ & & 1.47 & & .865 & 4.36 \\
\hline $\begin{array}{l}\text { helium shifted } \\
10 \% \text { reduction }\end{array}$ & & 1.34 & & .870 & 4.33 \\
\hline $\begin{array}{l}\text { helium shifted } \\
25 \% \text { reduction }\end{array}$ & & 1.48 & & .889 & 3.58 \\
\hline
\end{tabular}

The attached figures show the 3-D variations of the neutral densities and other quantities. 
$10 \%$ reduction in duct height

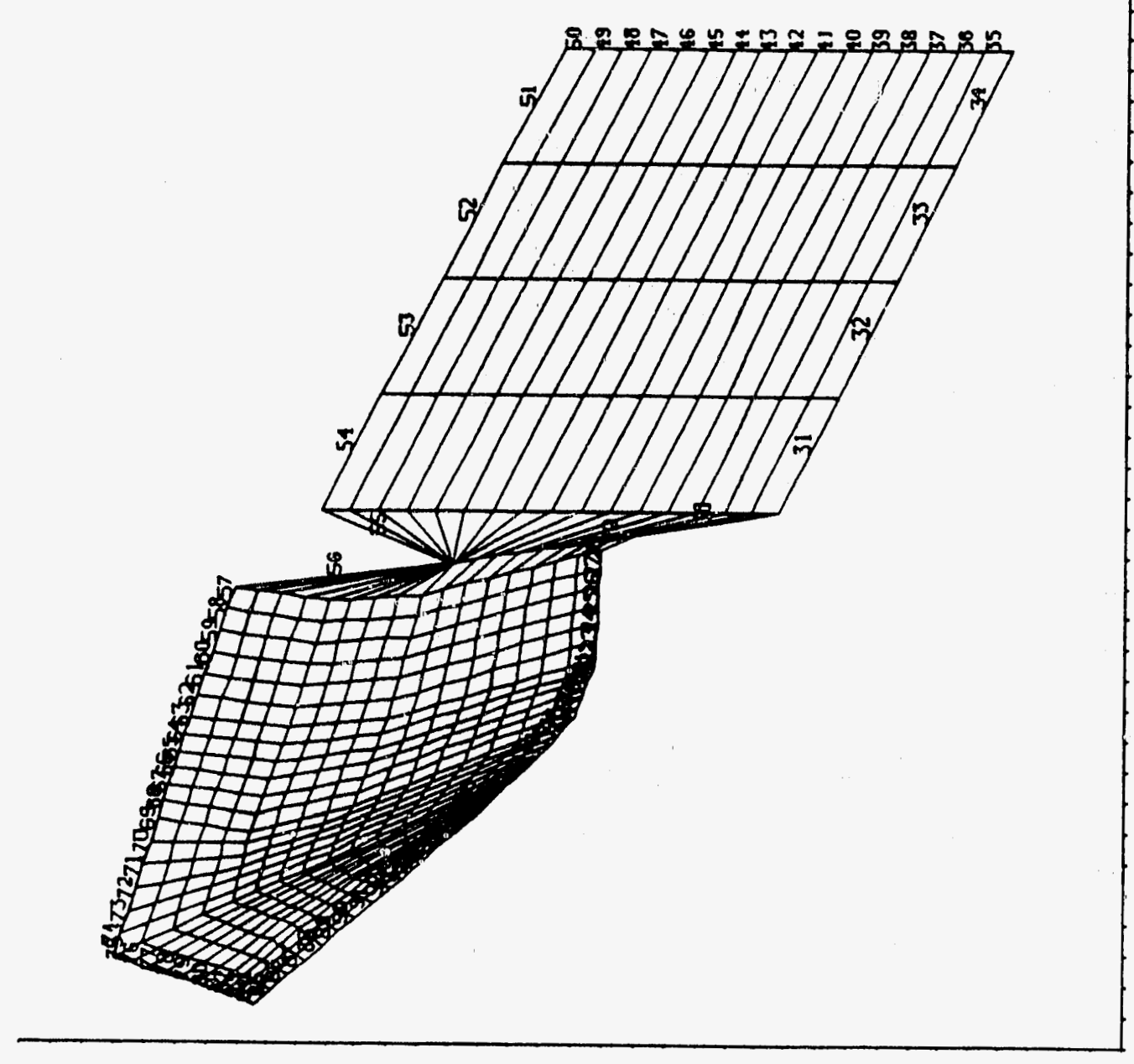




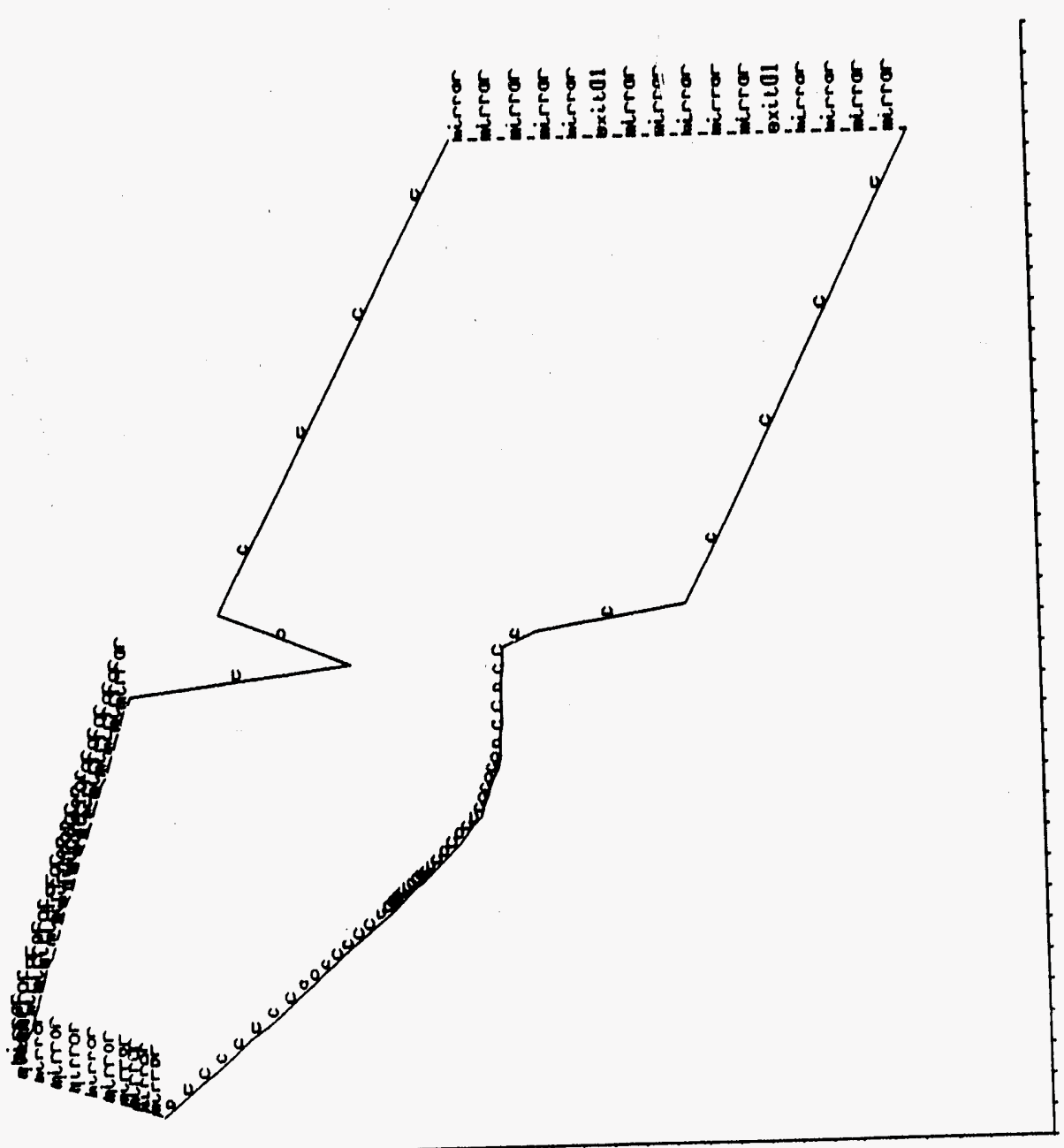




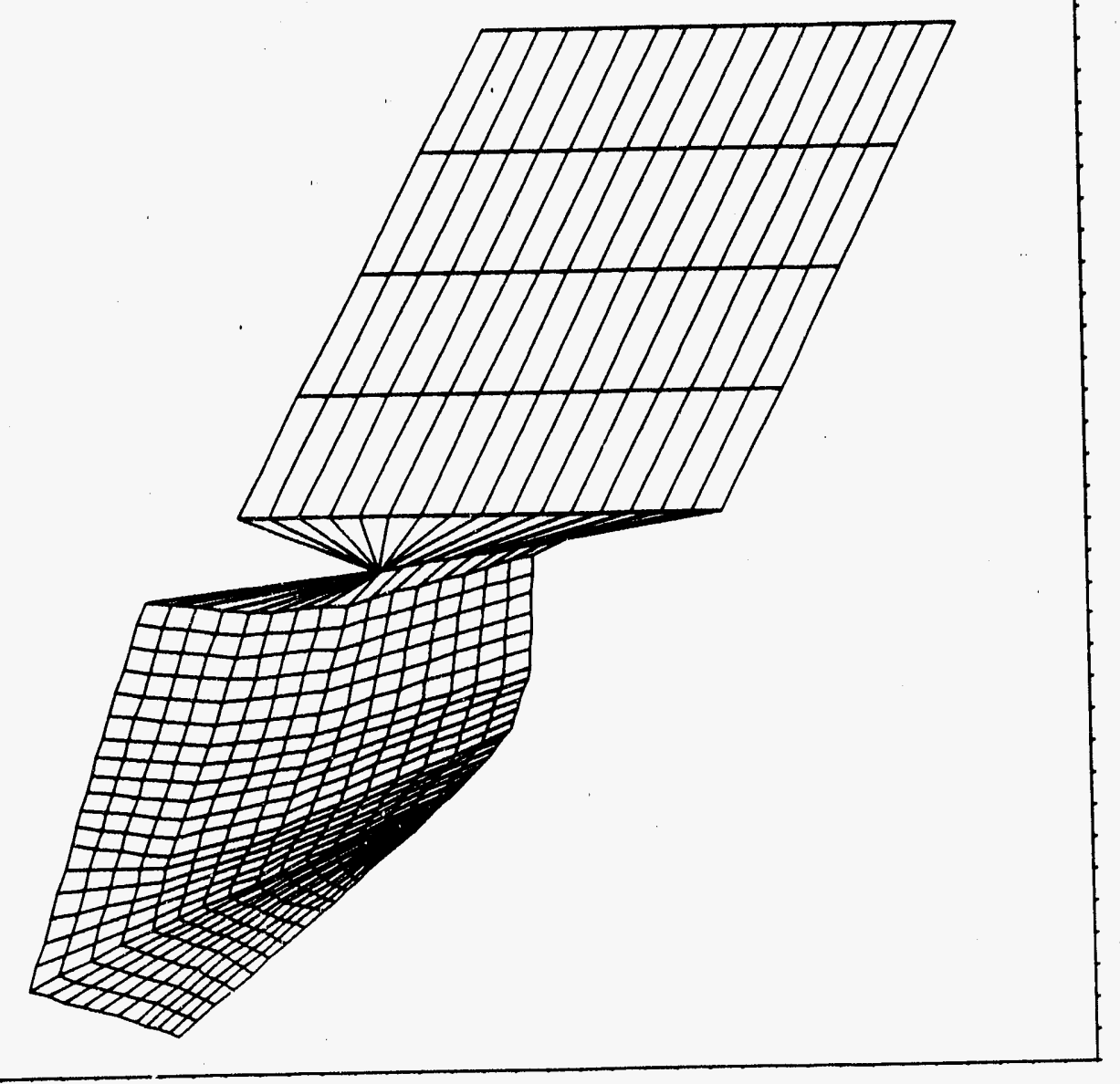














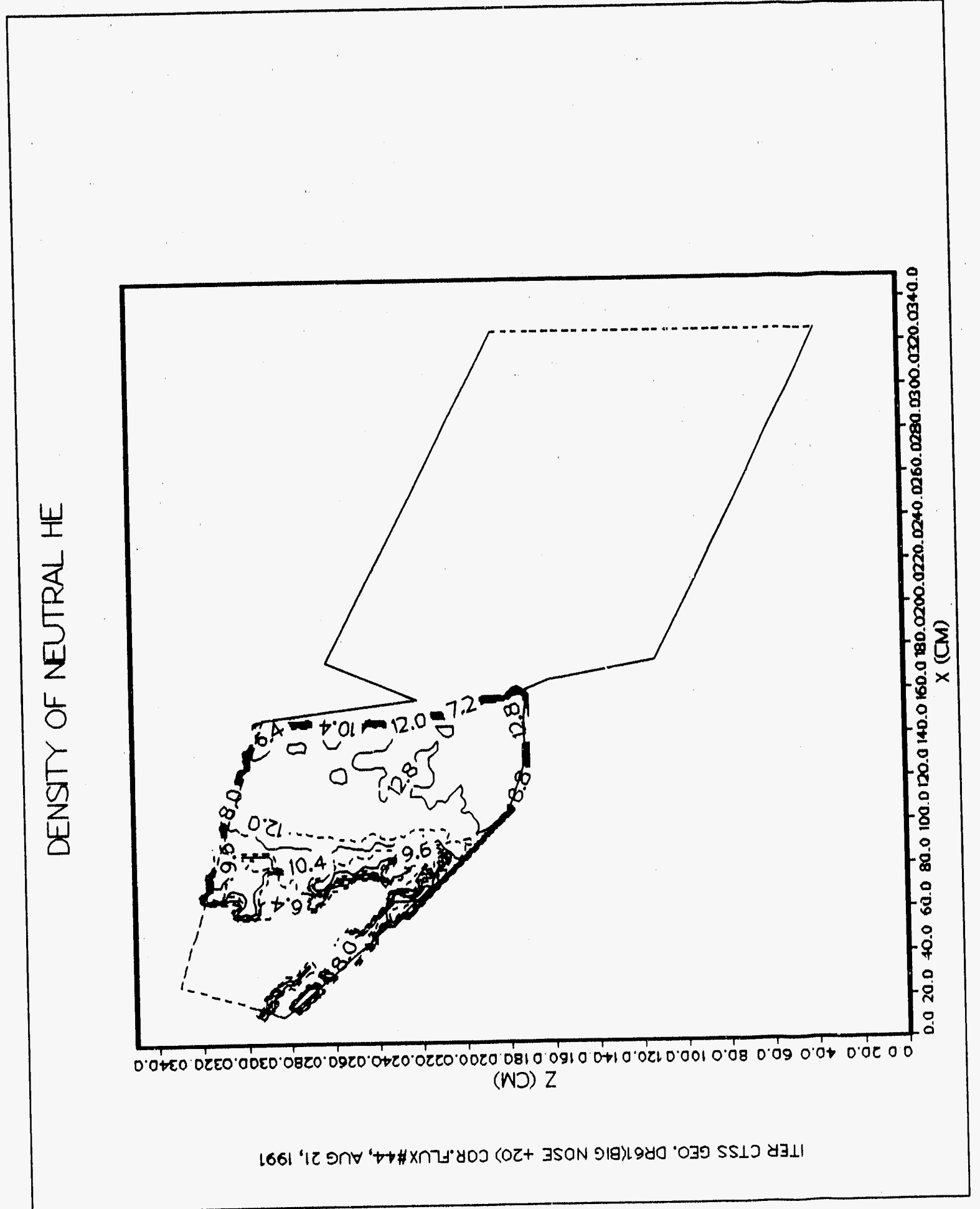




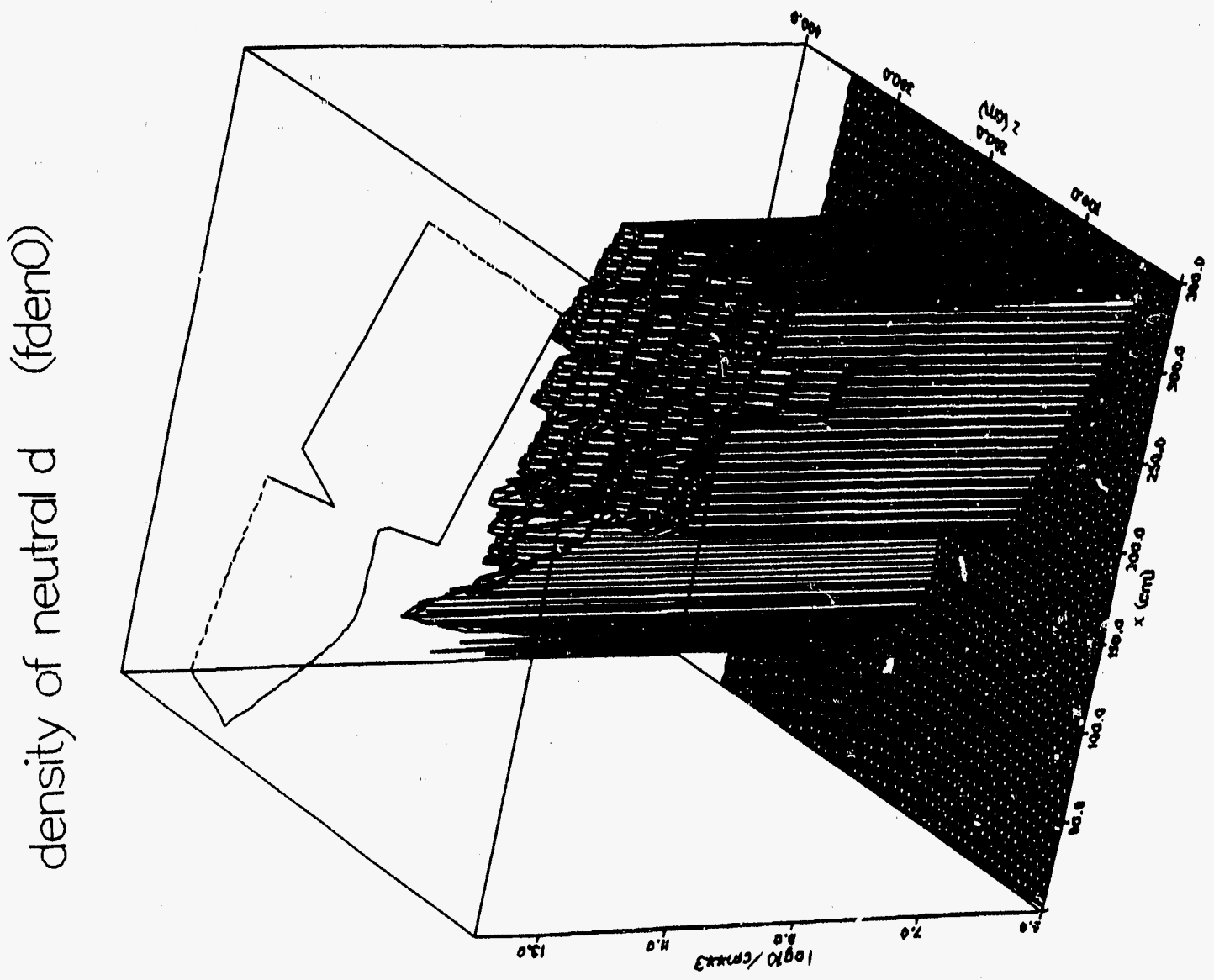

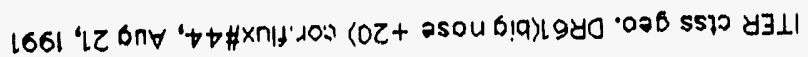




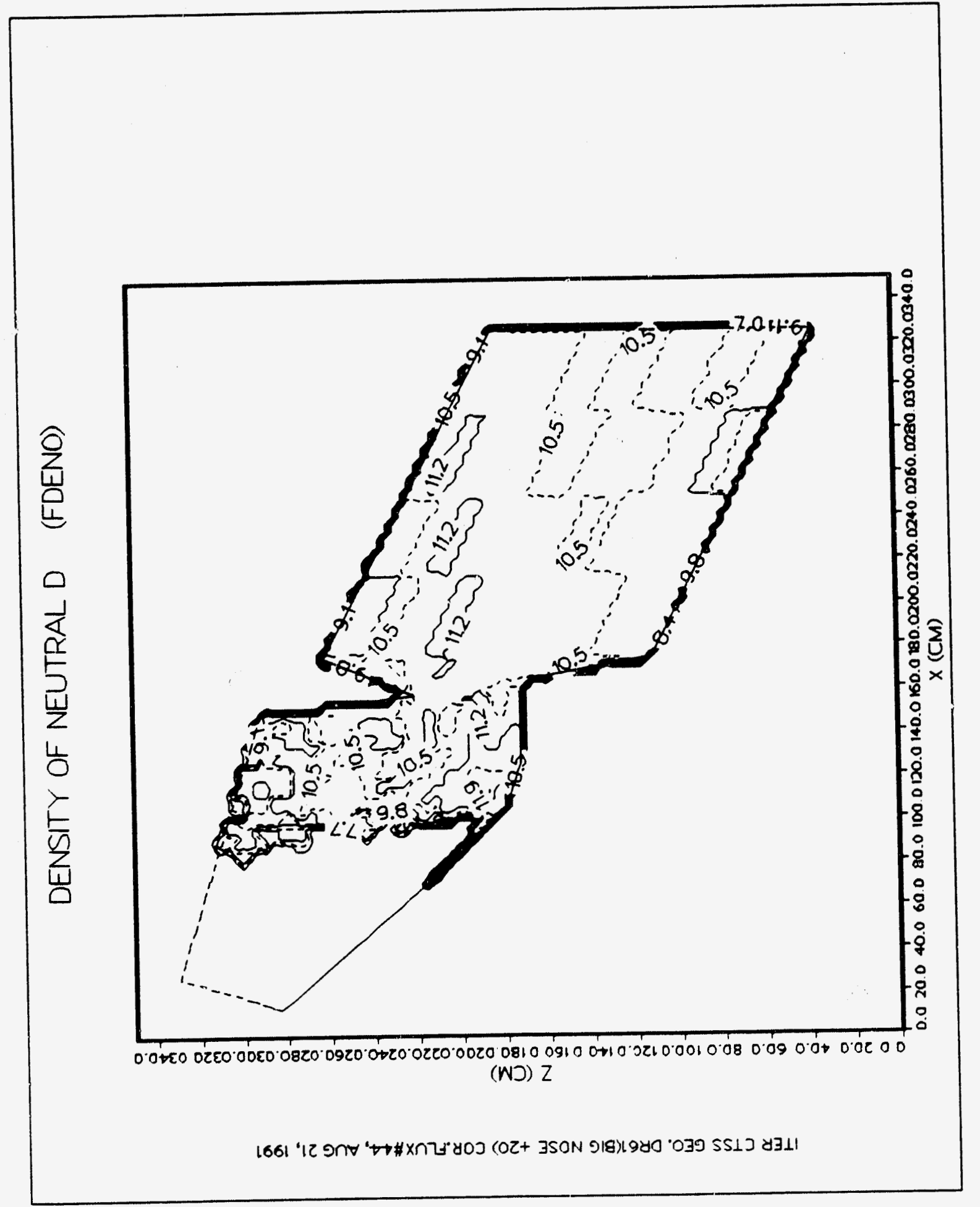




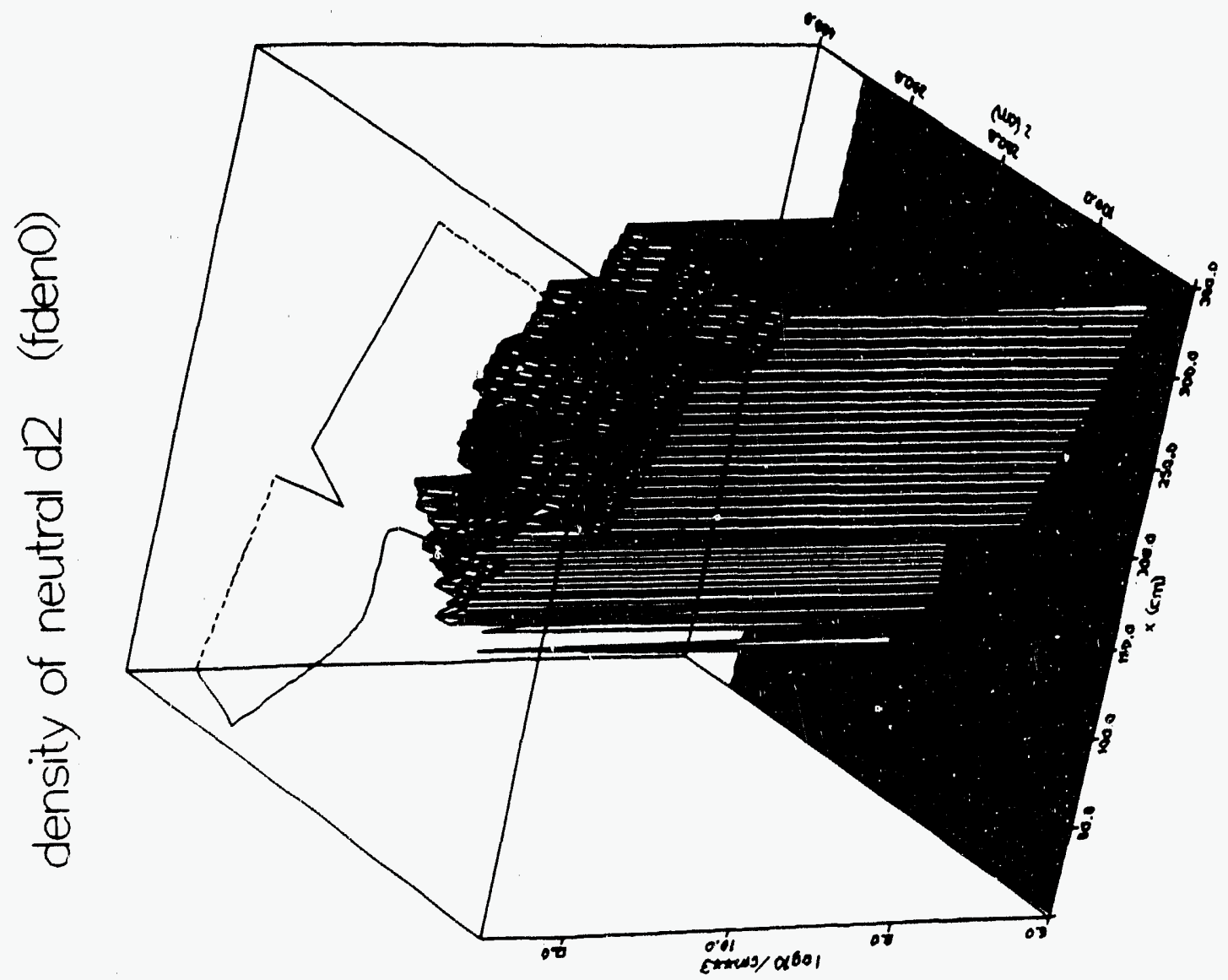

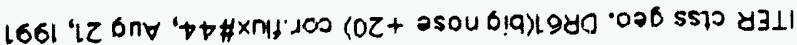




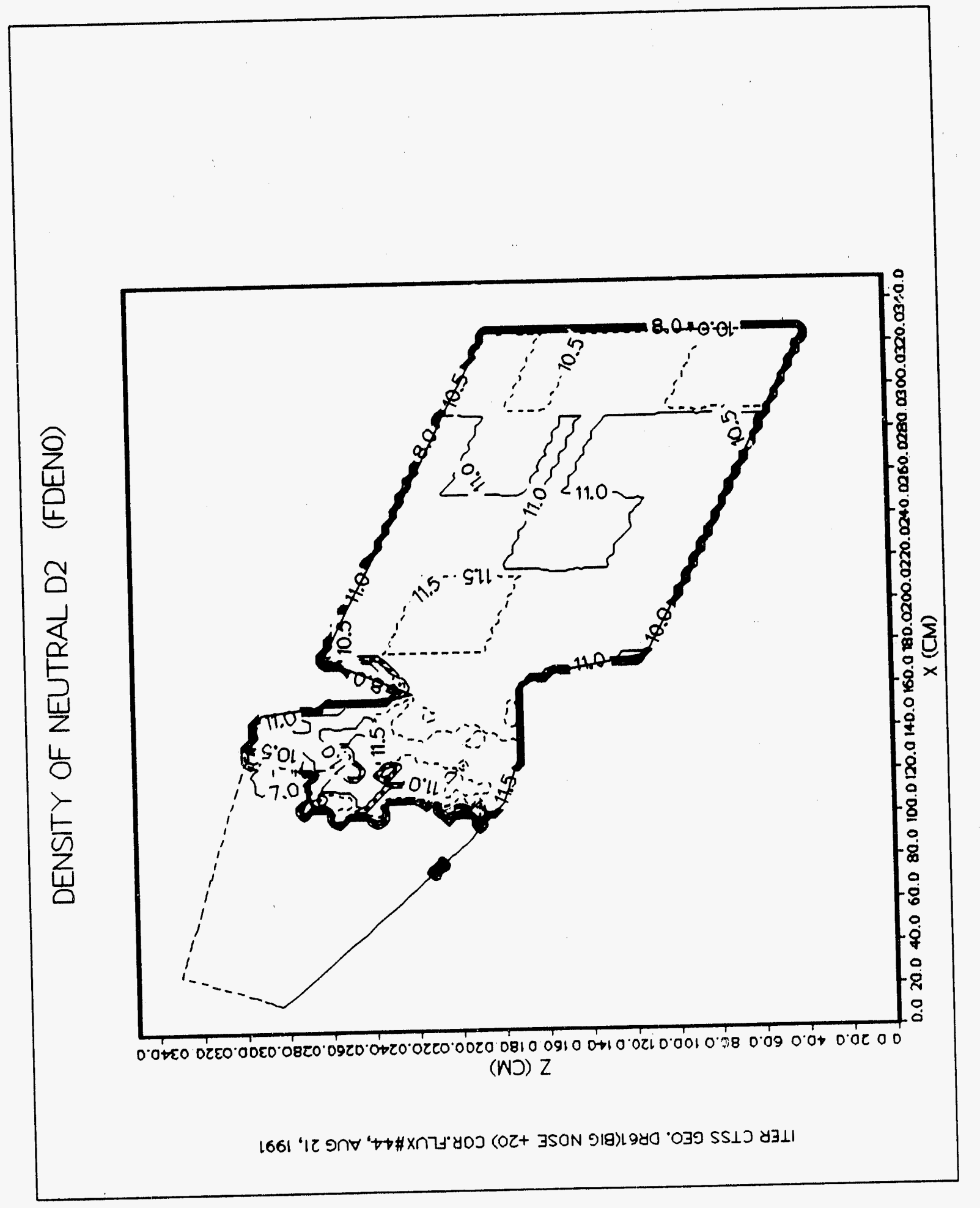




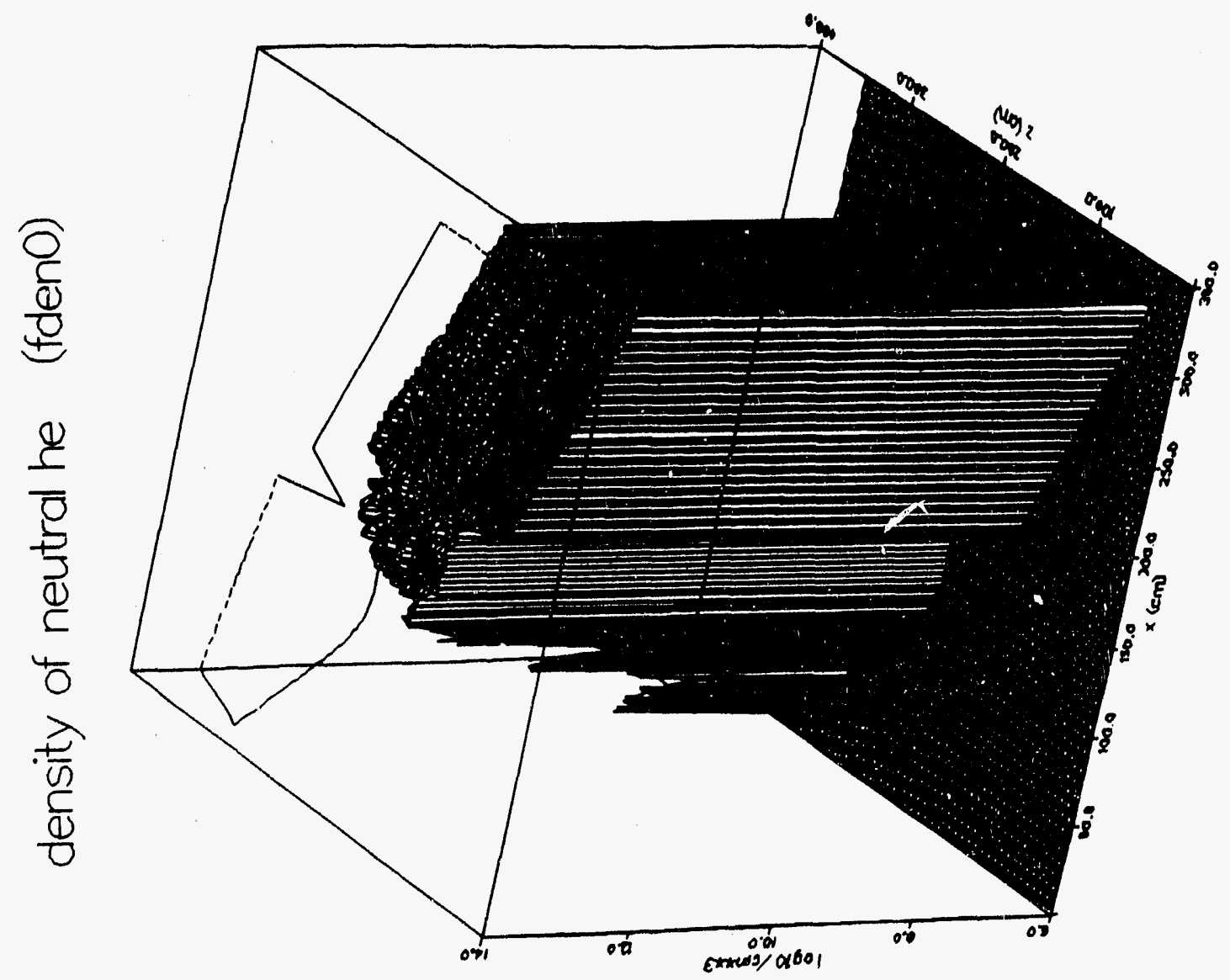

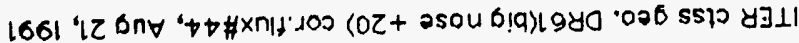




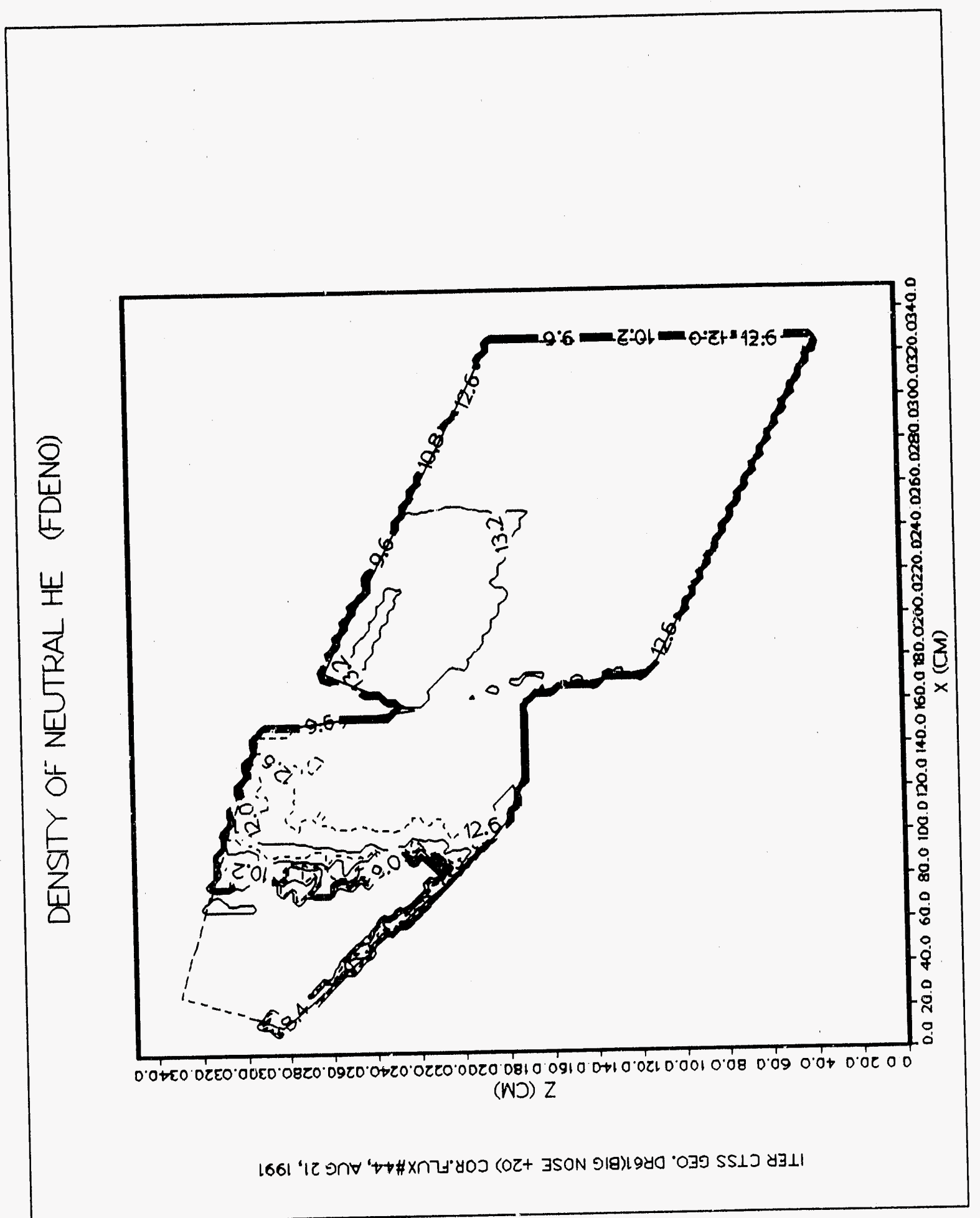




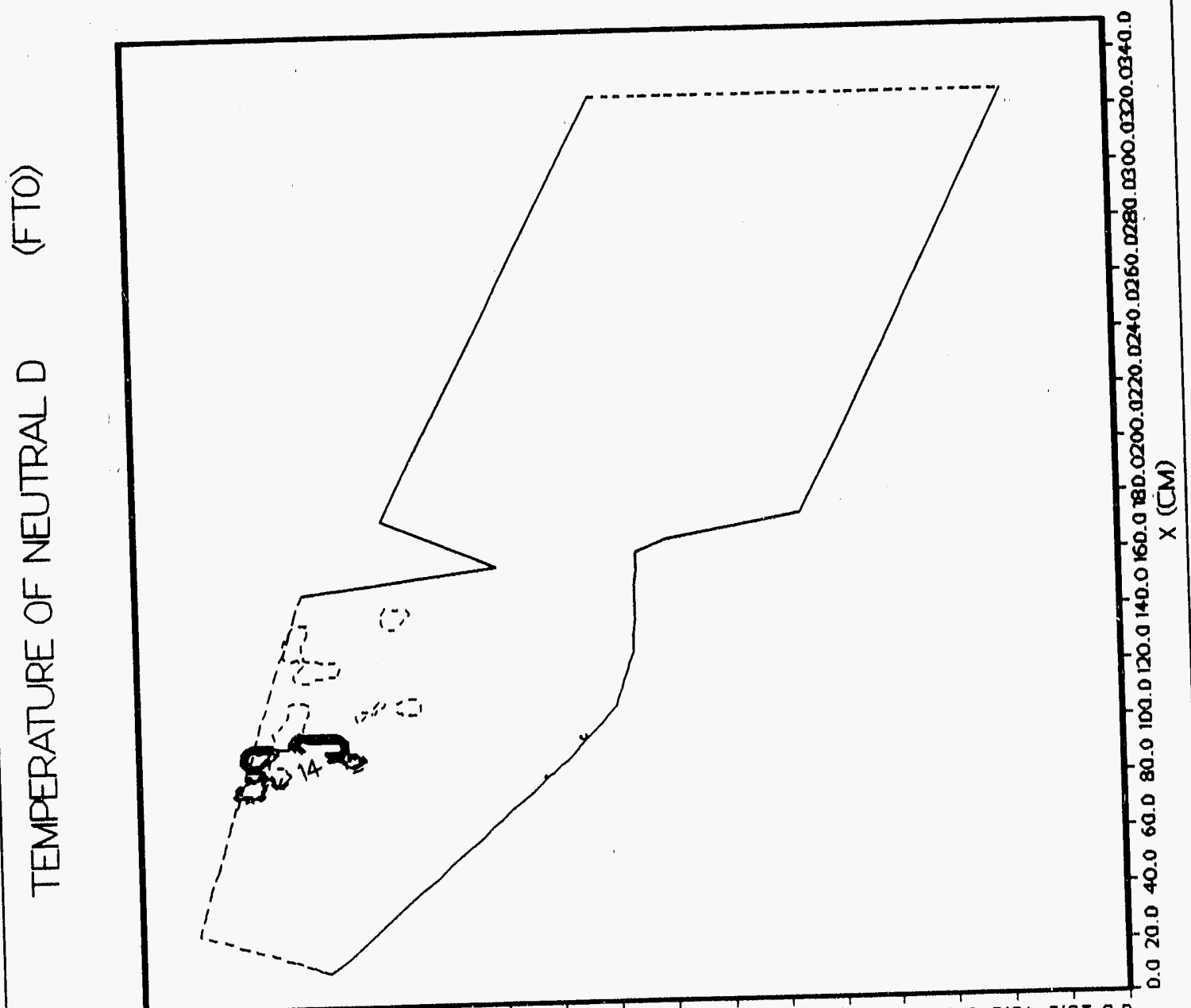

$0.0+50.0250 .0050 .0820 .0920 .0+20.0220 .0020 .081009100010 .0210 .0010 .080 .090 .040 .0200$ (WD) Z

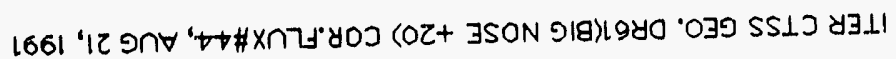




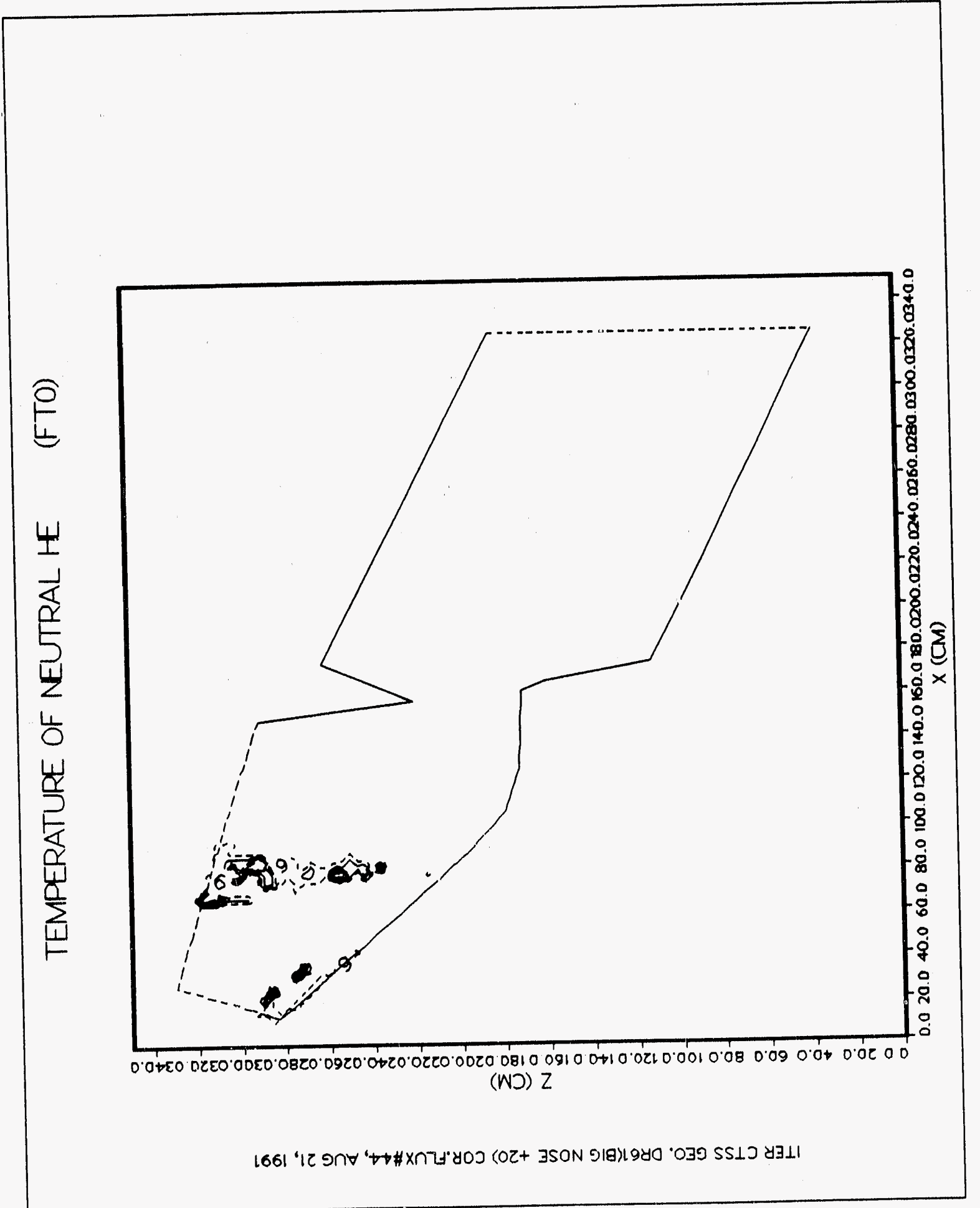




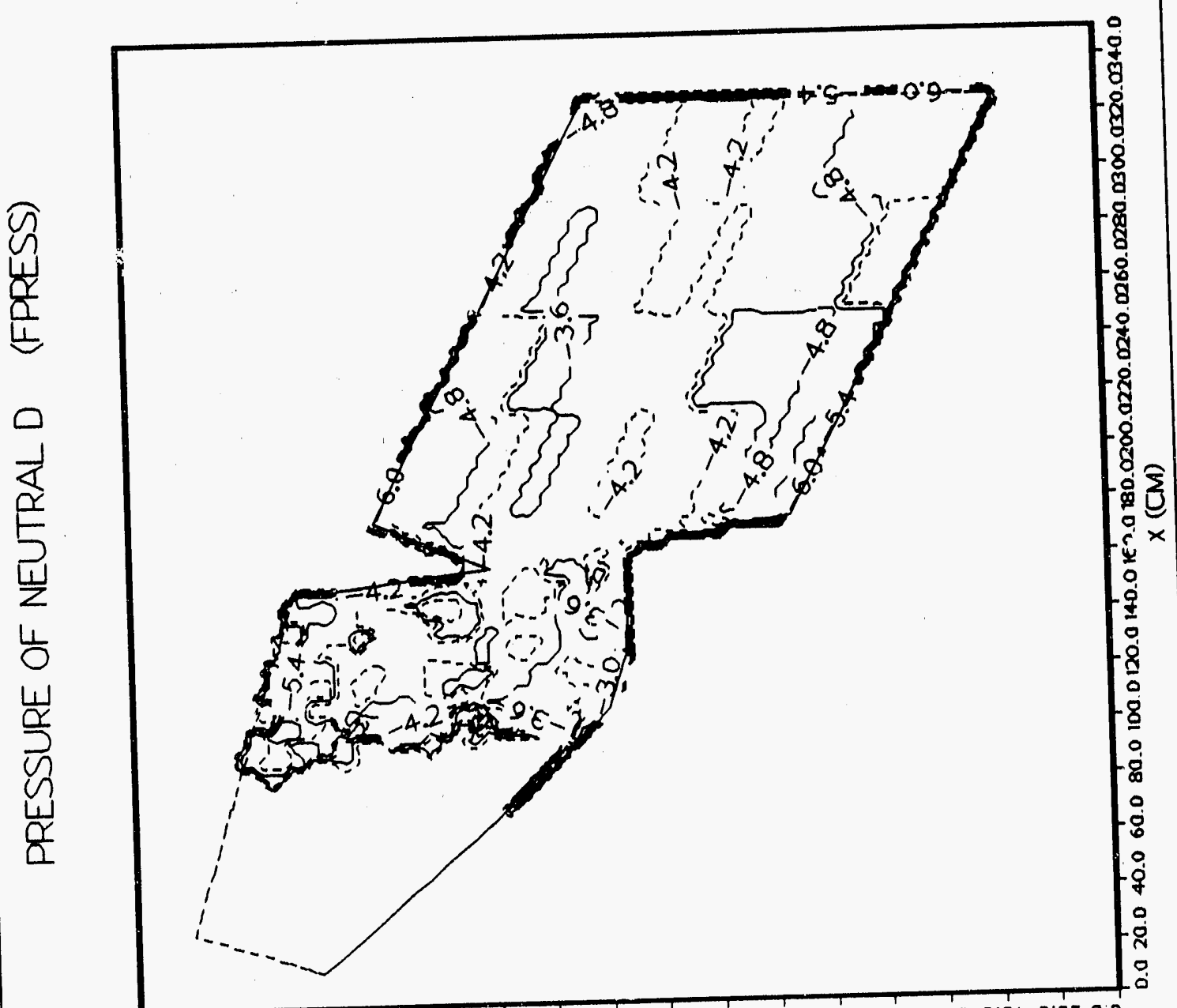

$0.0+60.0250 .0050 .0820 .0920 .0+20.0280 .0020 .0810 .09100+10.0210 .0010 .080 .090 .040 .060 .0$ (n!) Z

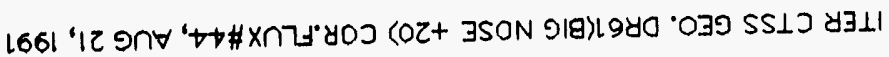




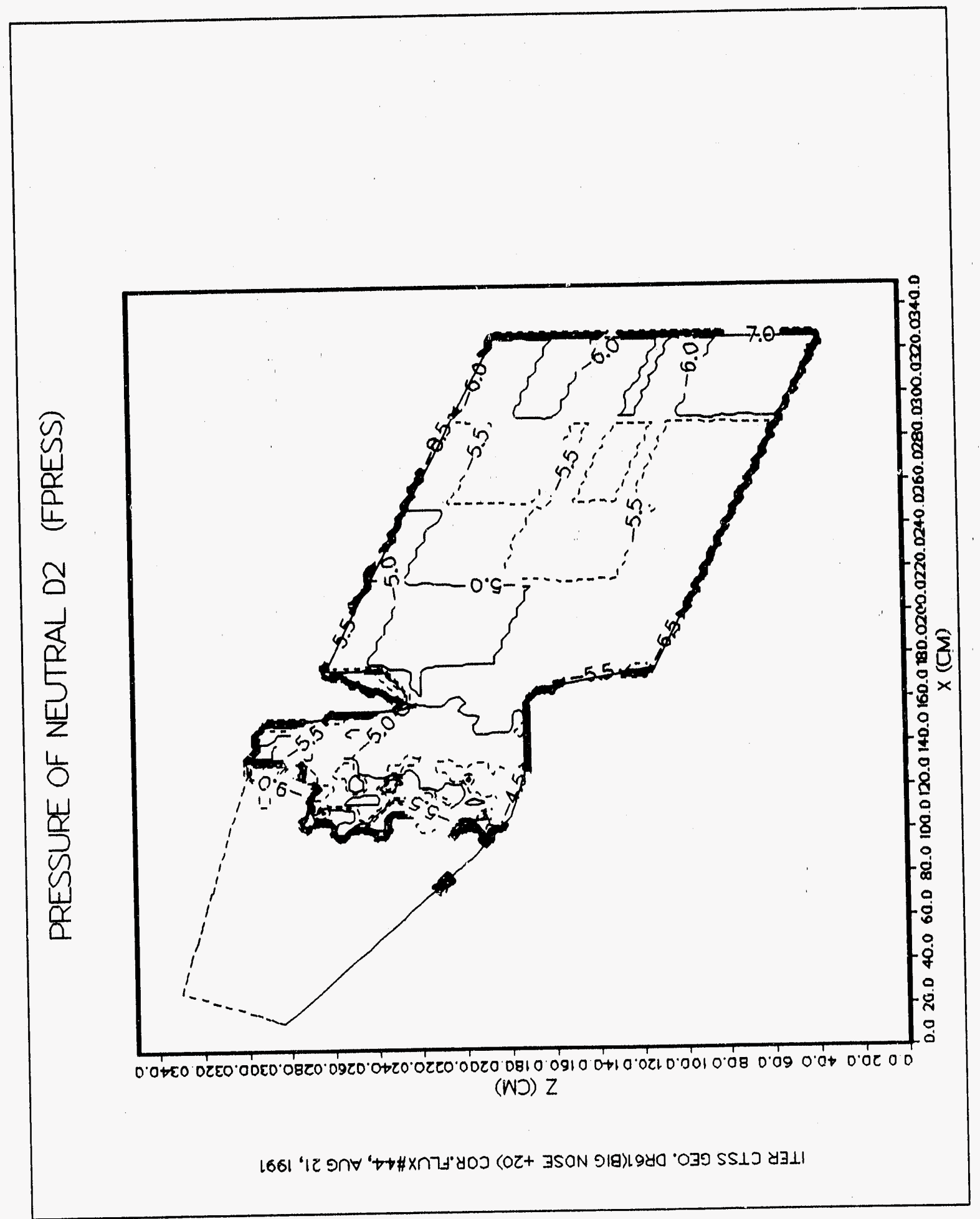





\section{$25 \%$ reduction in duct height}

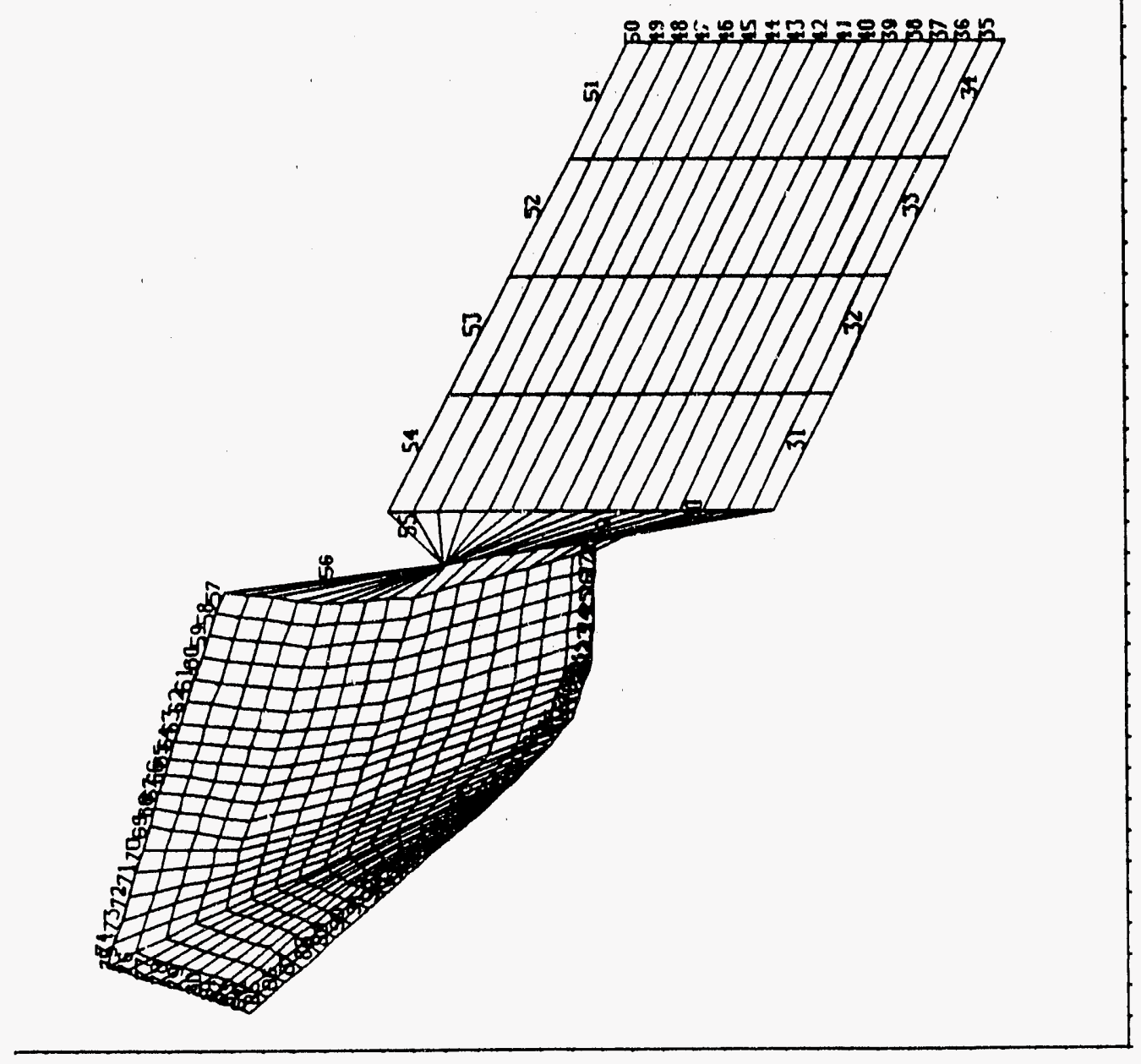




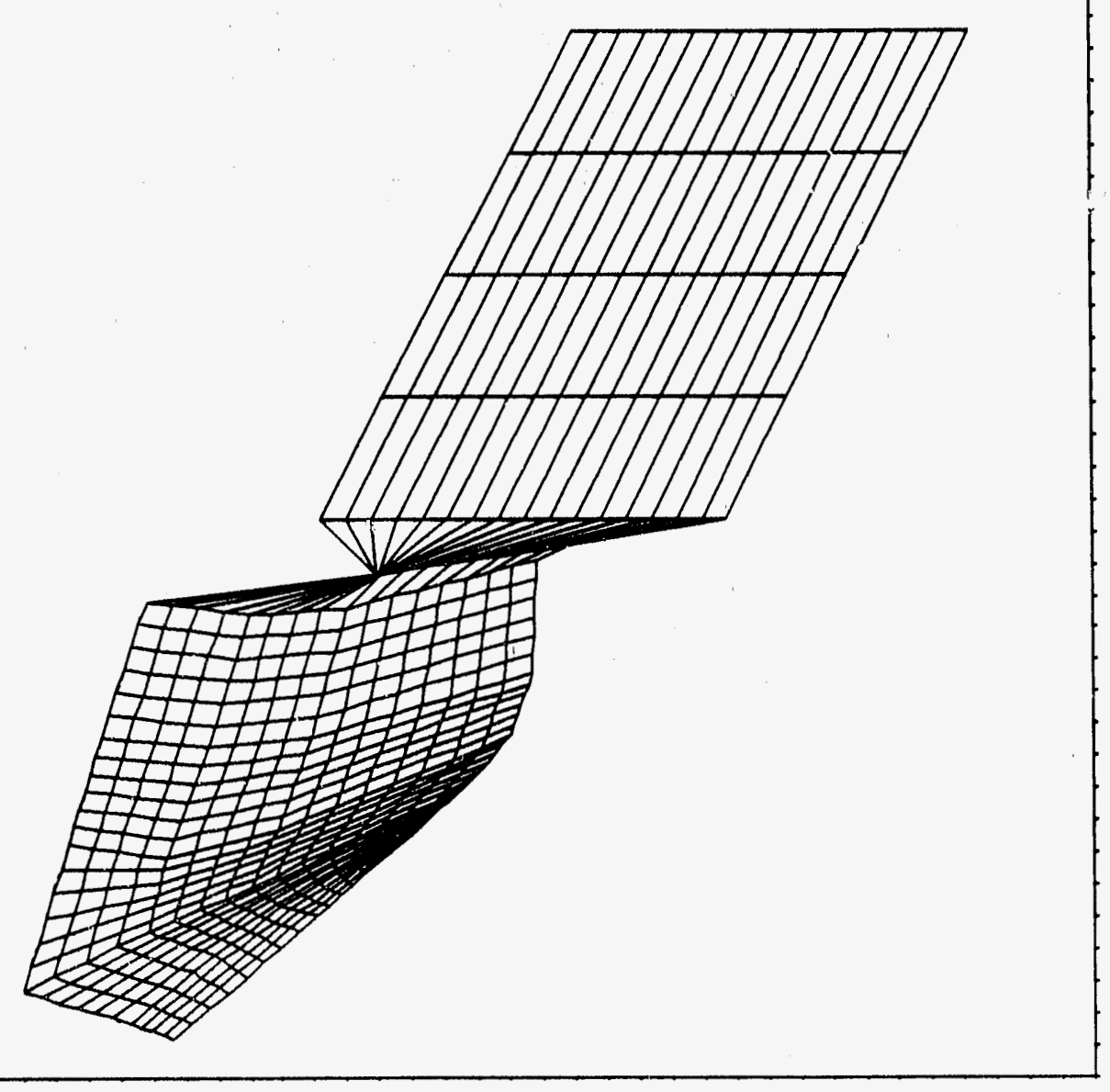




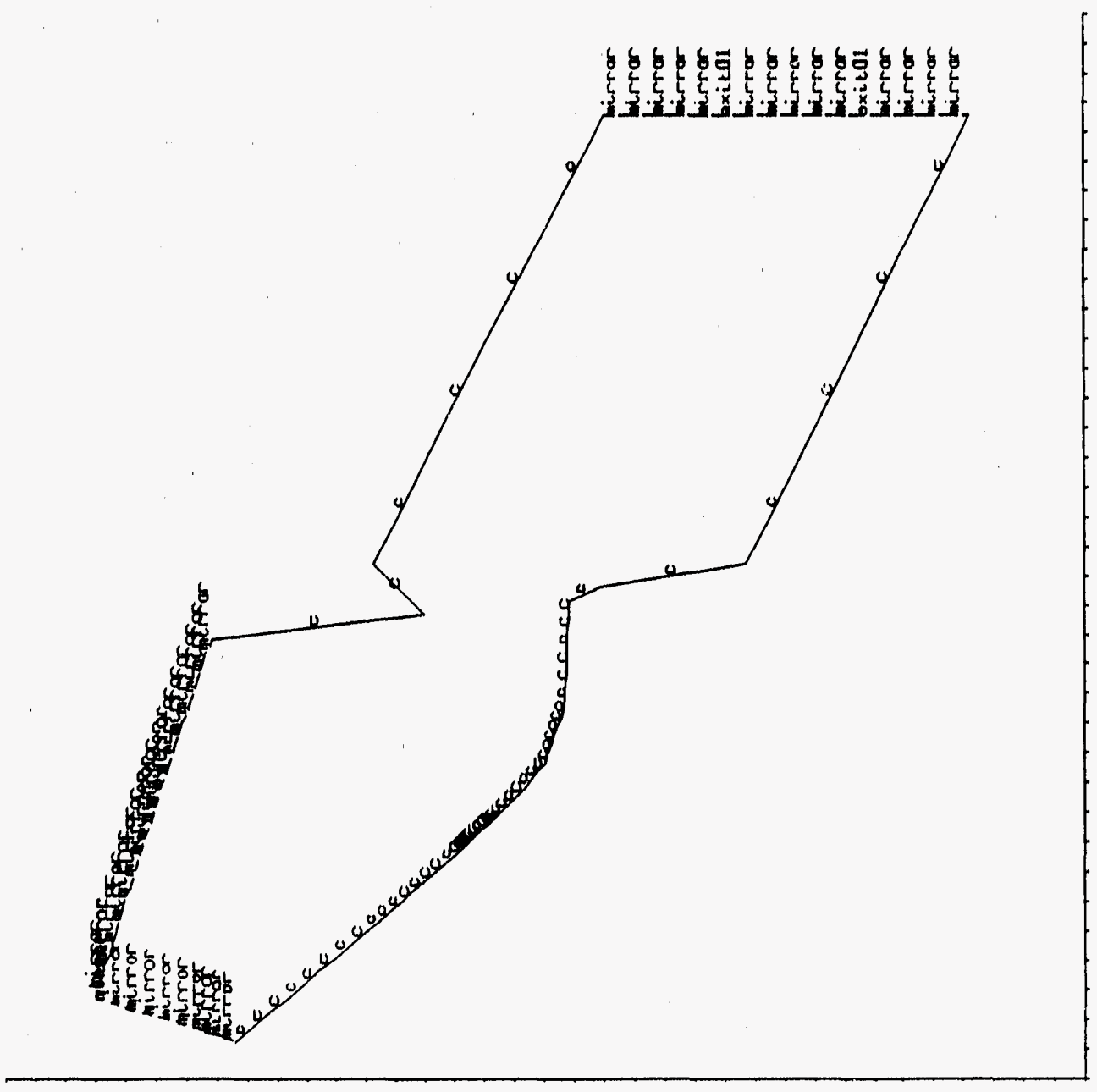




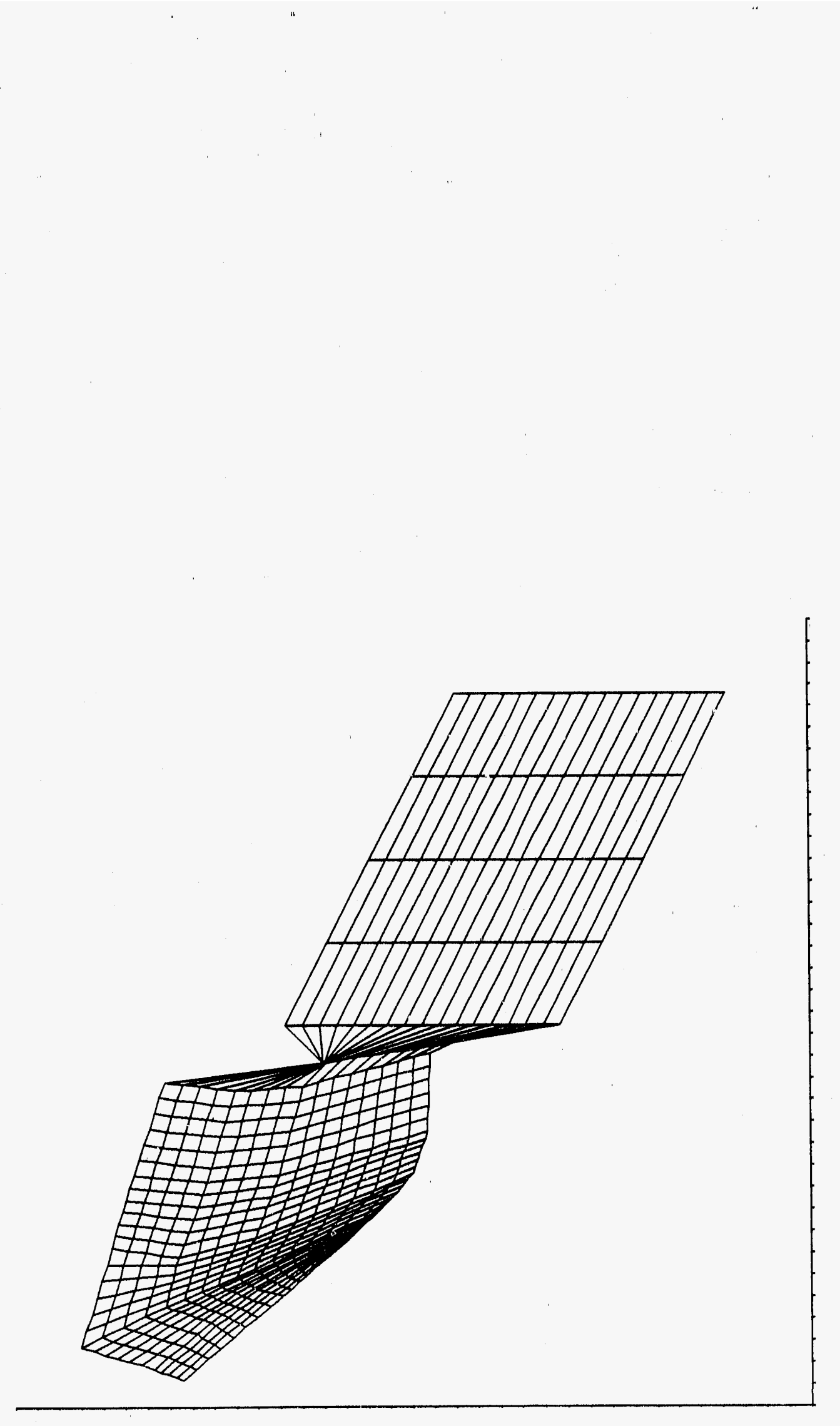




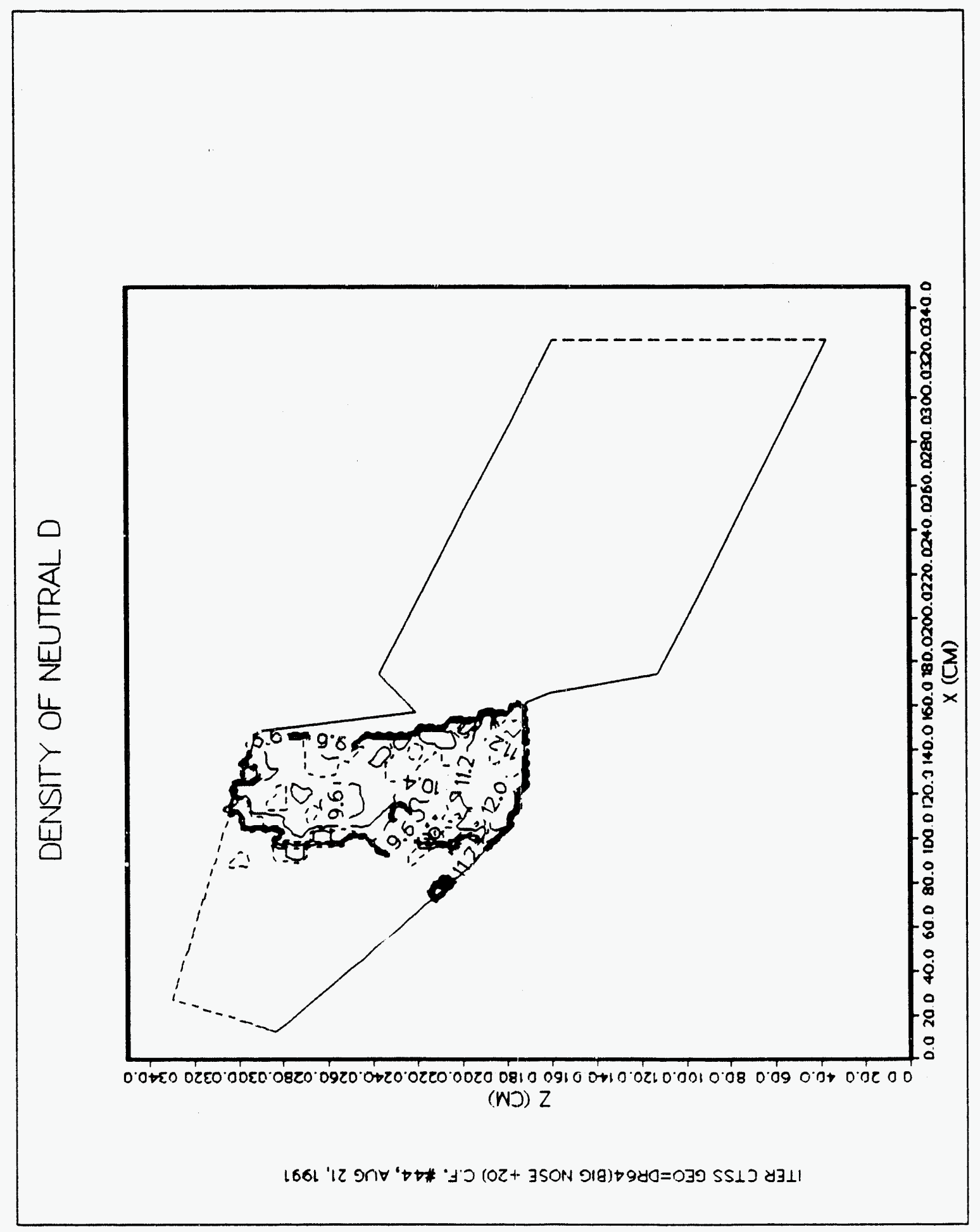




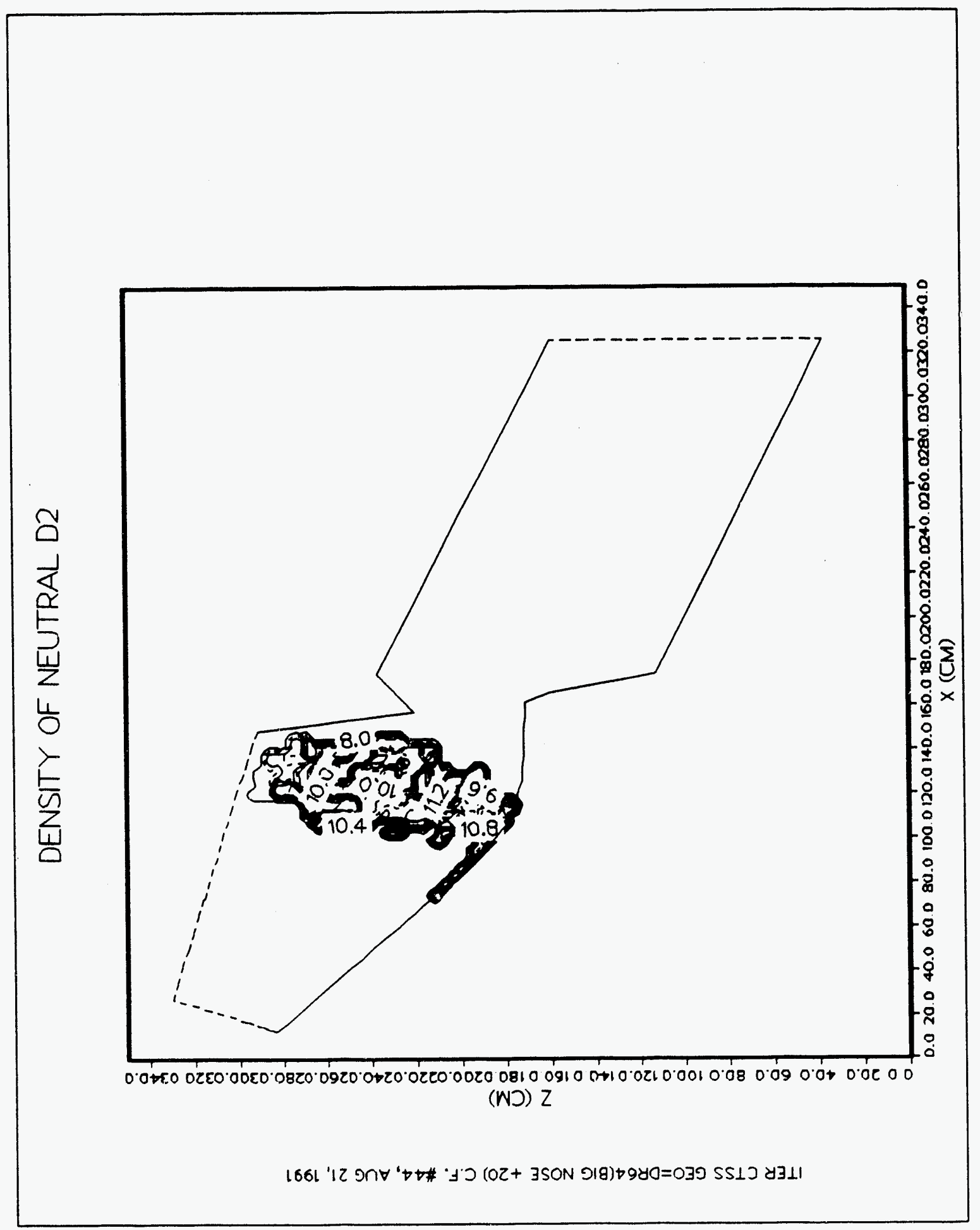




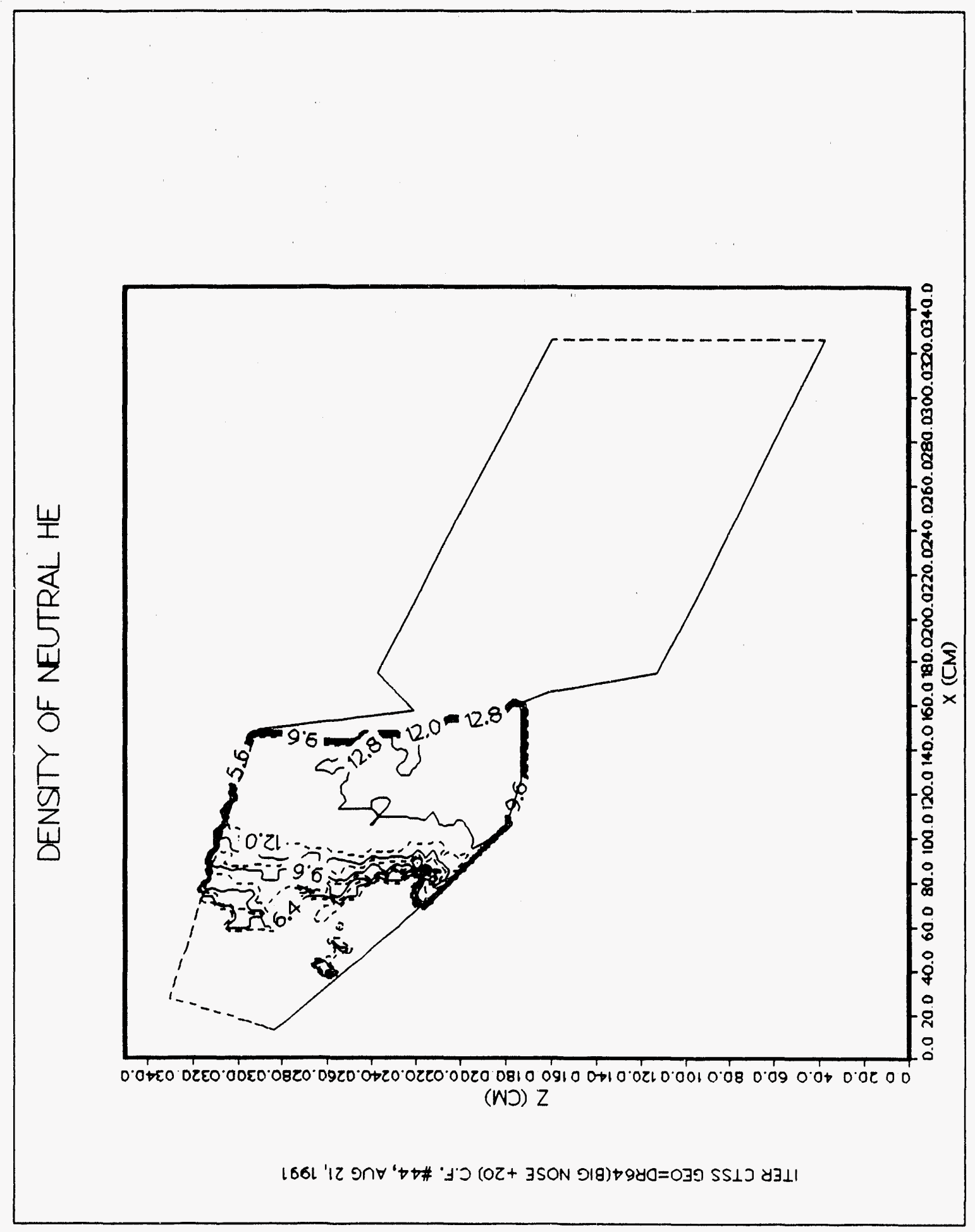




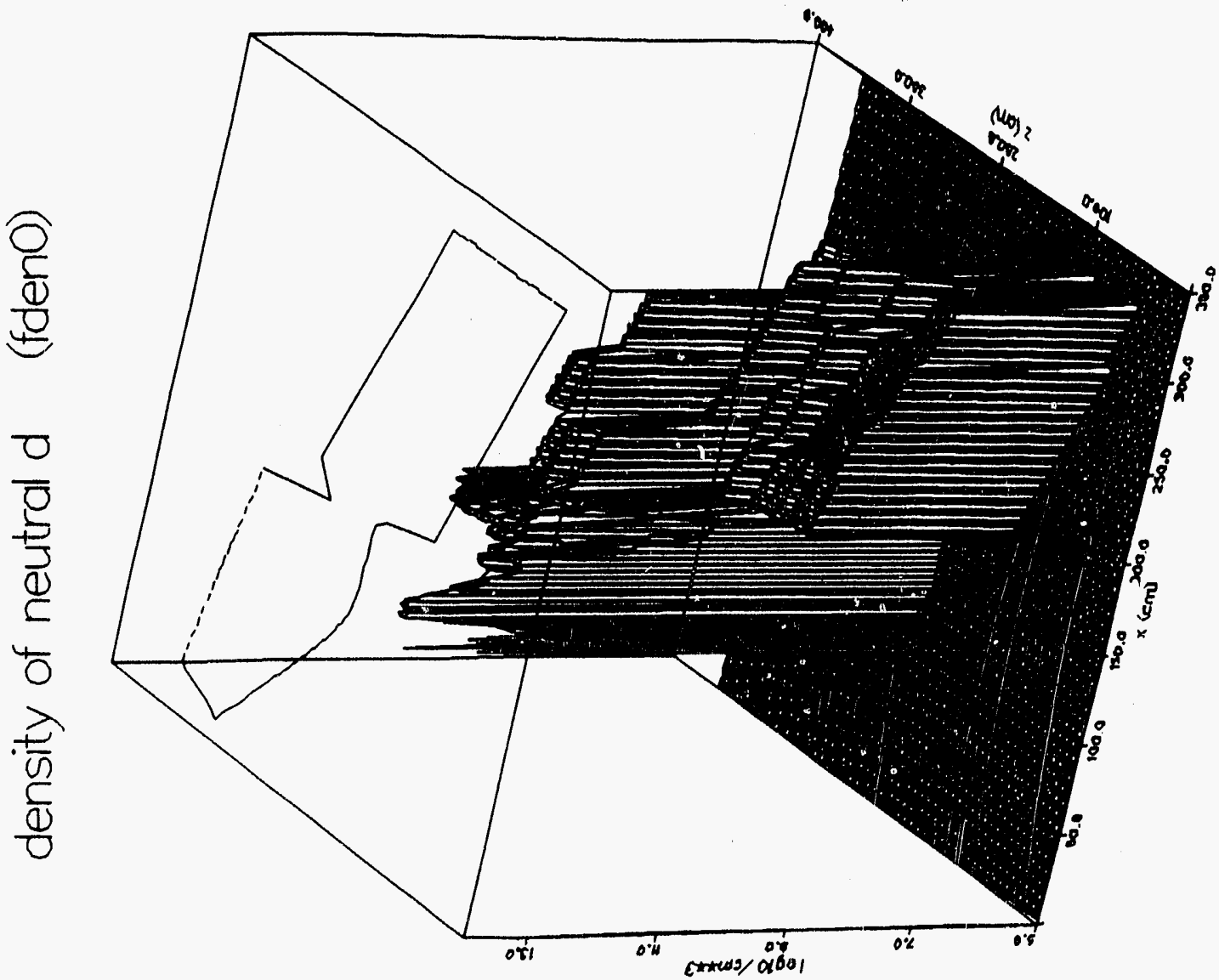

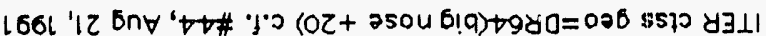




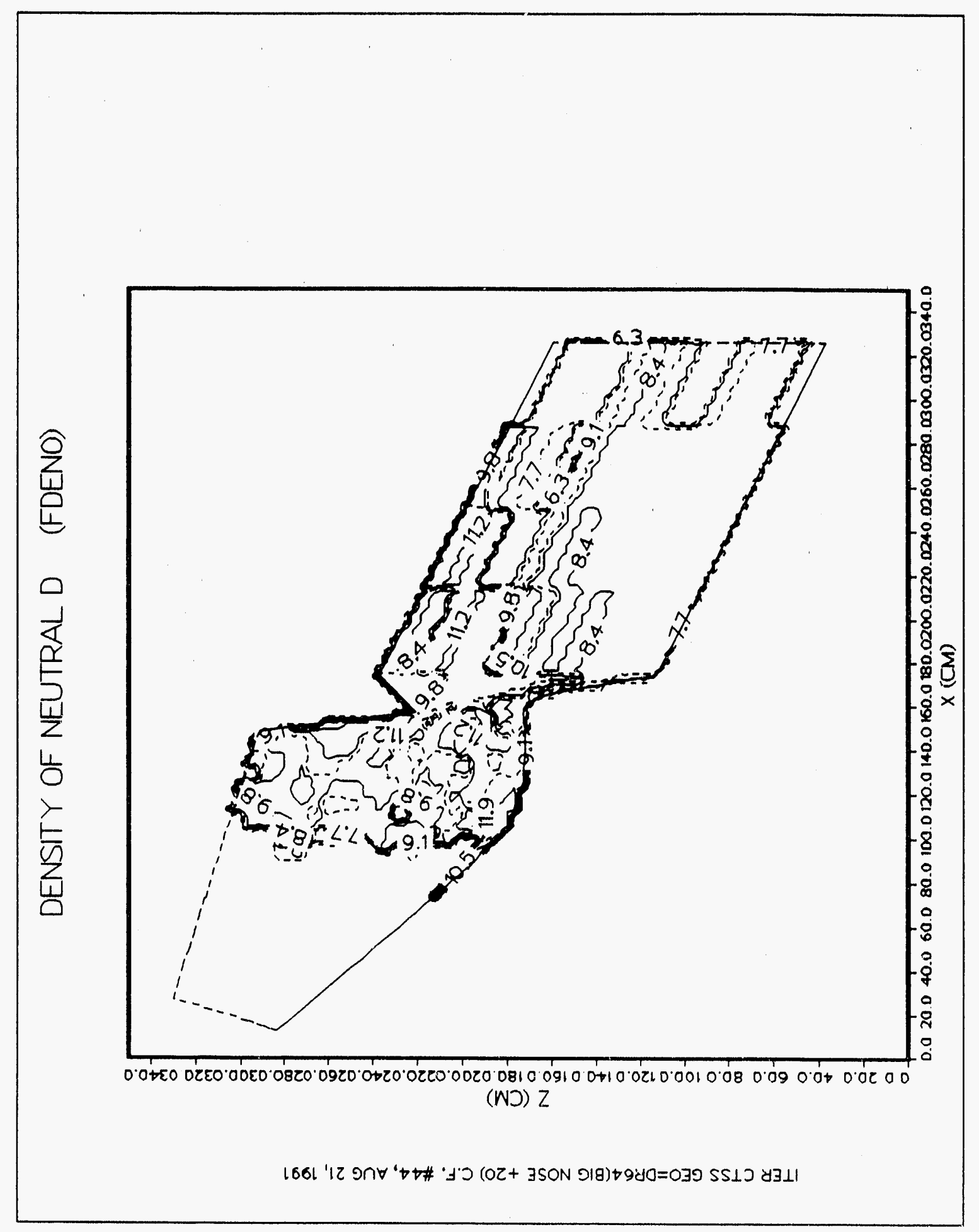




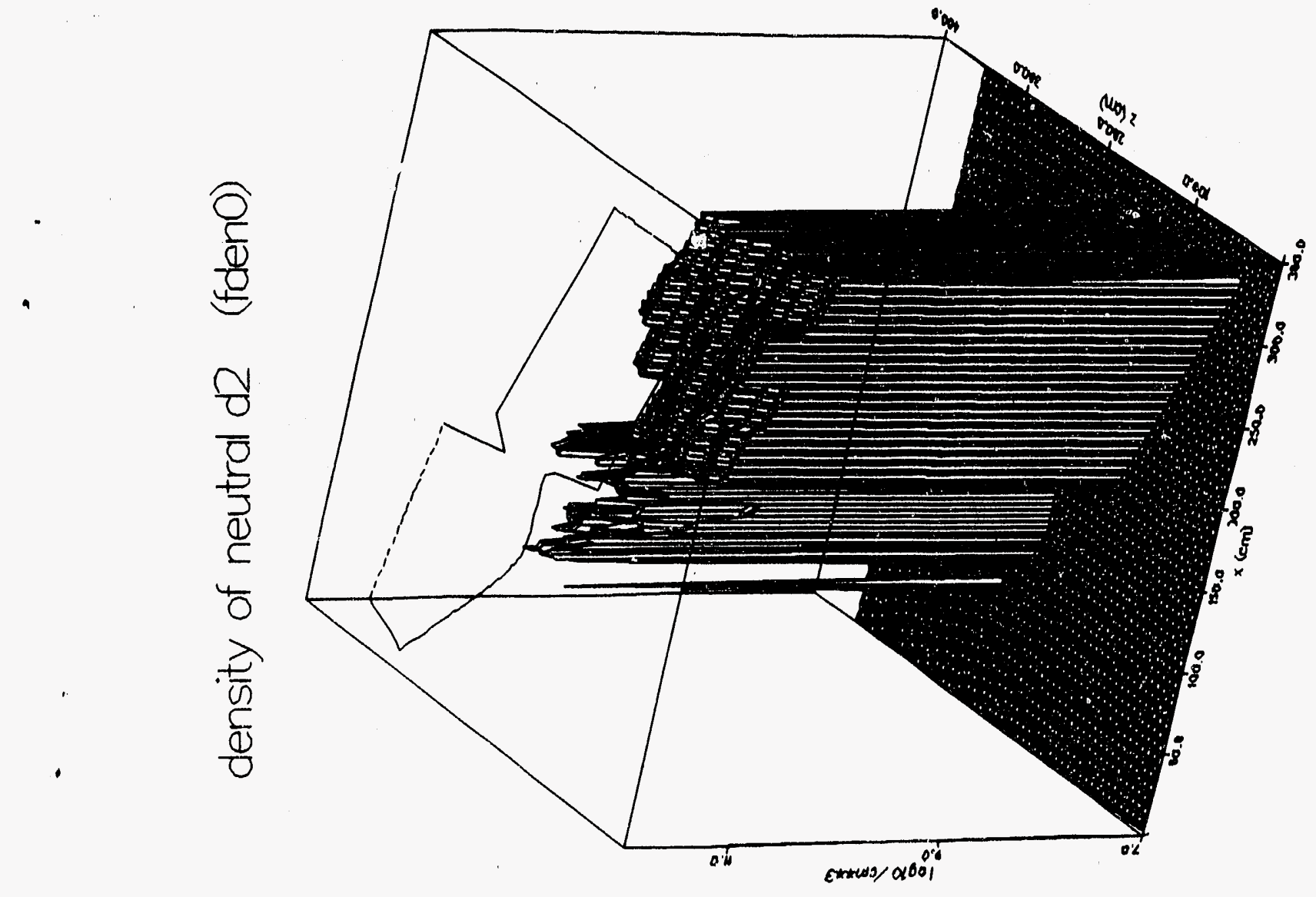

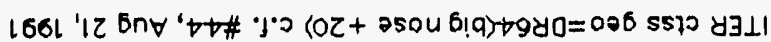




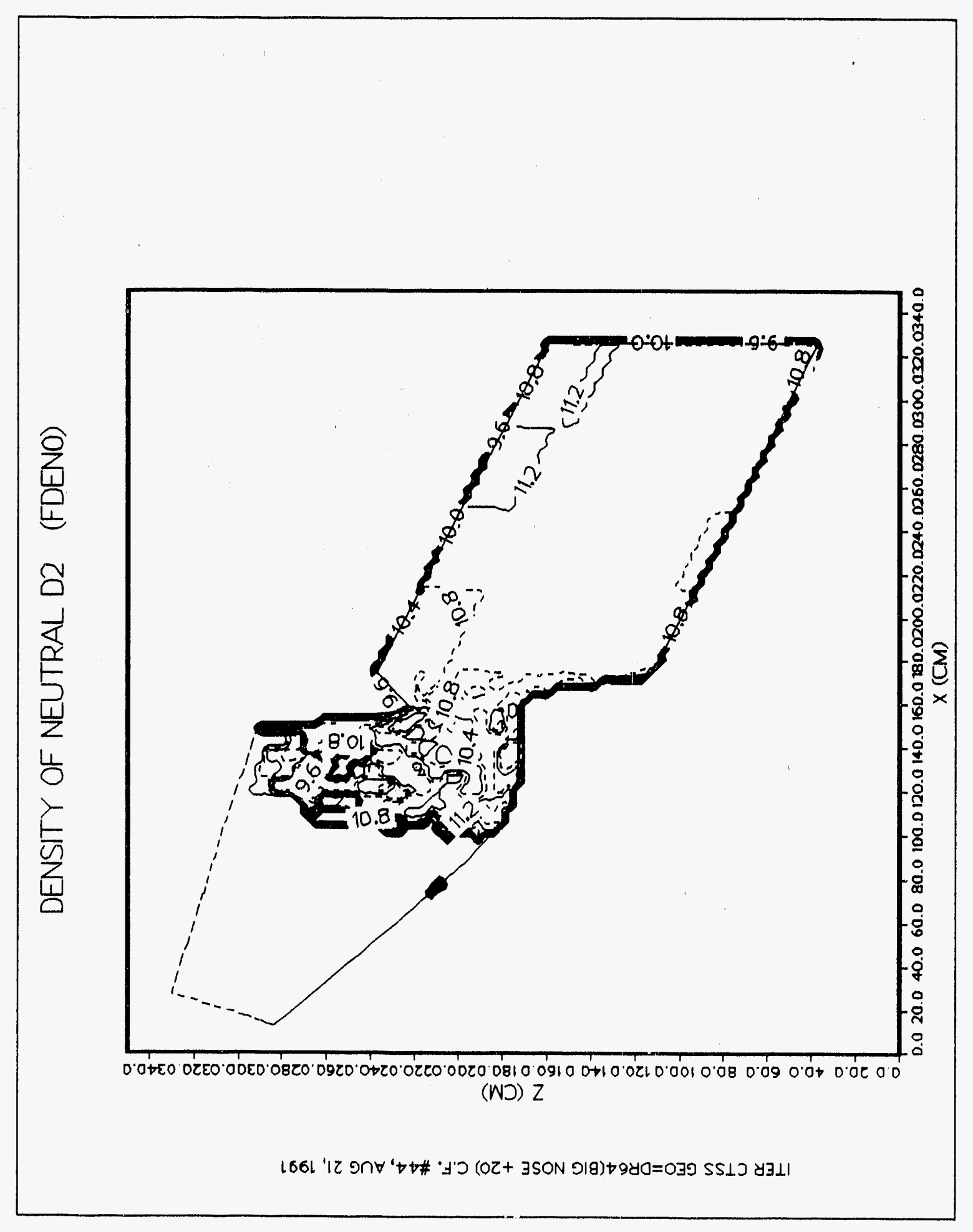




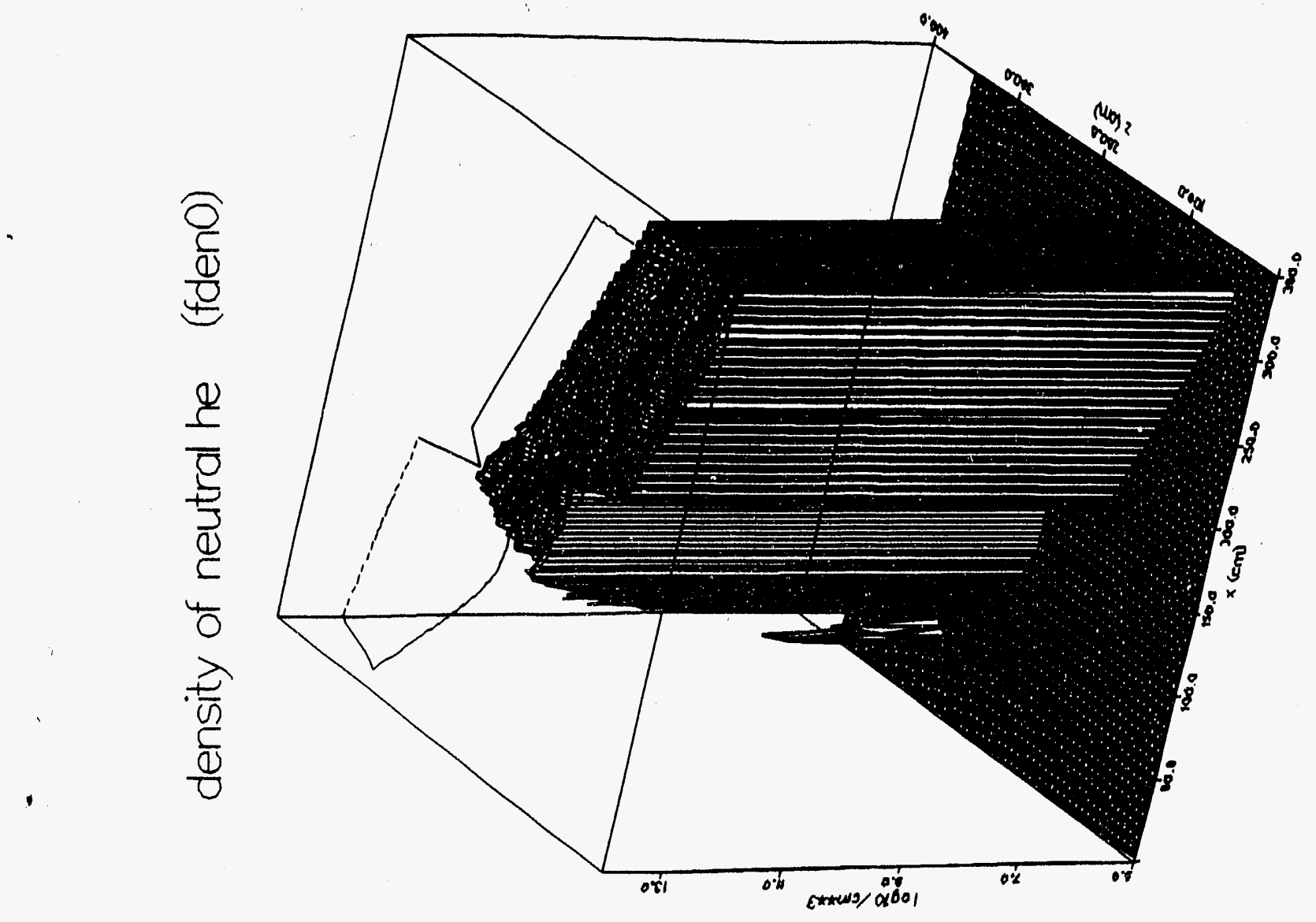

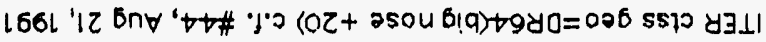




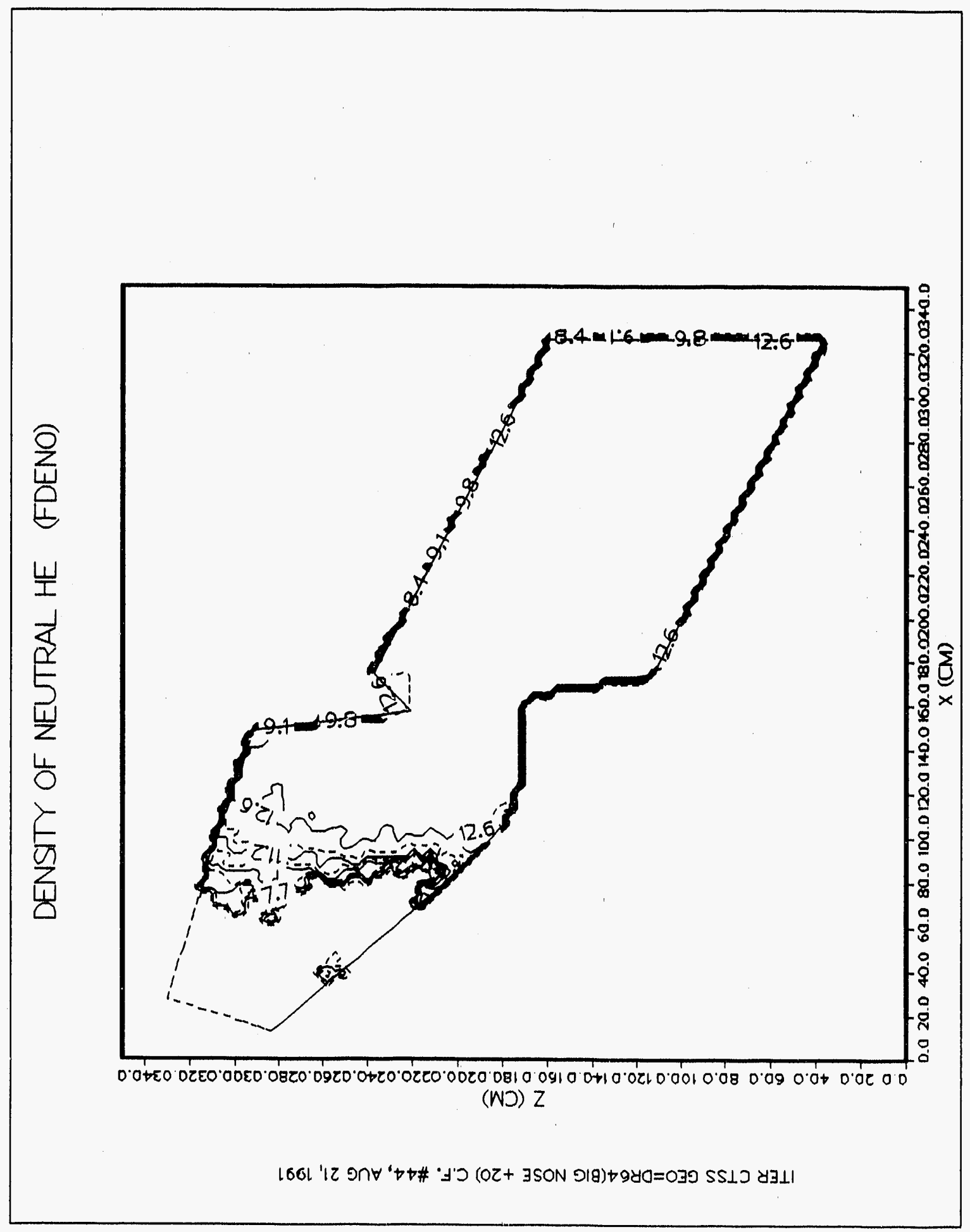




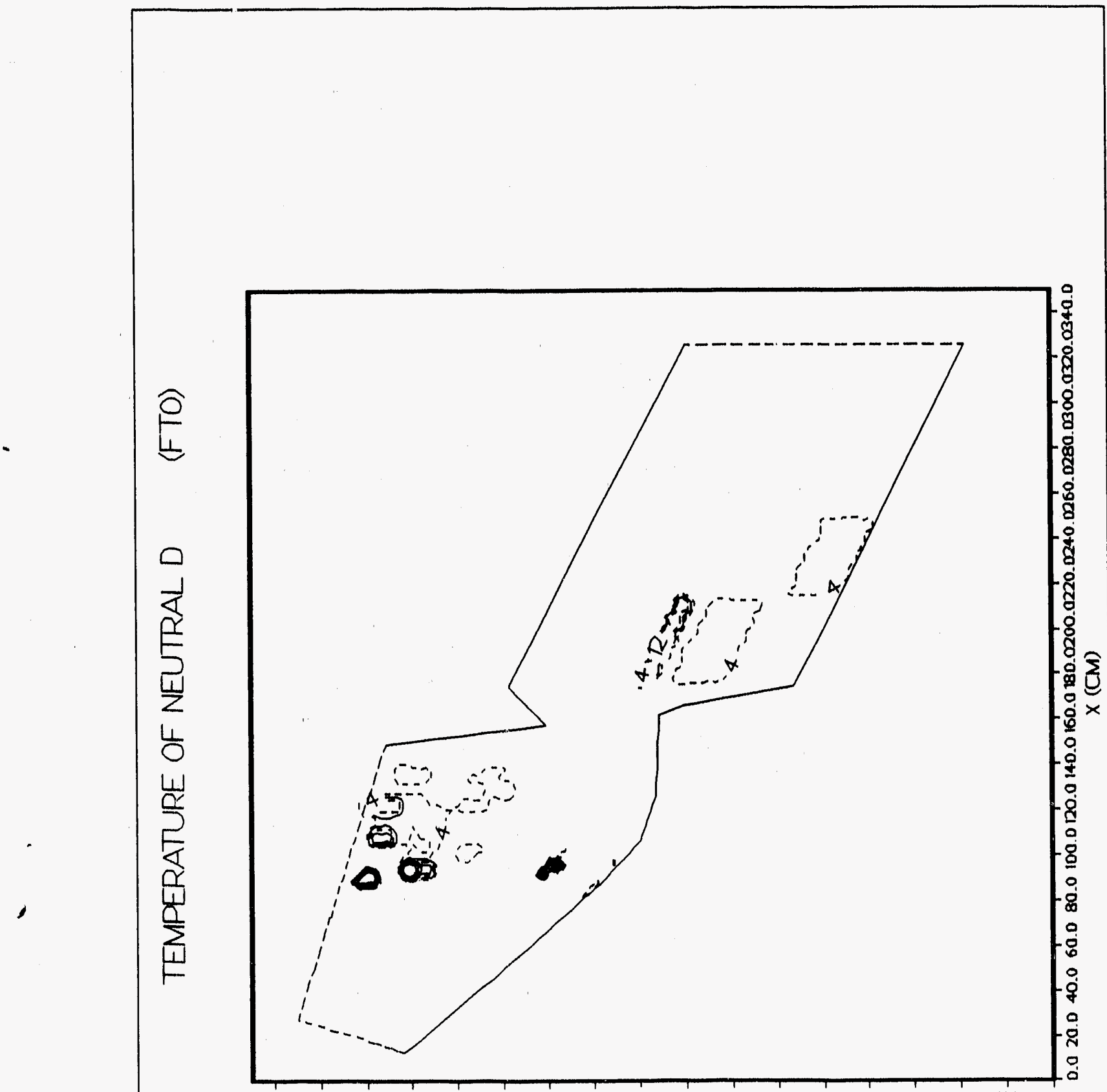

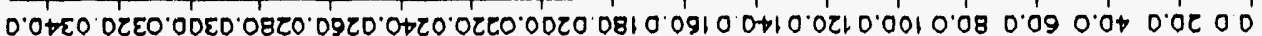
(WD) Z 







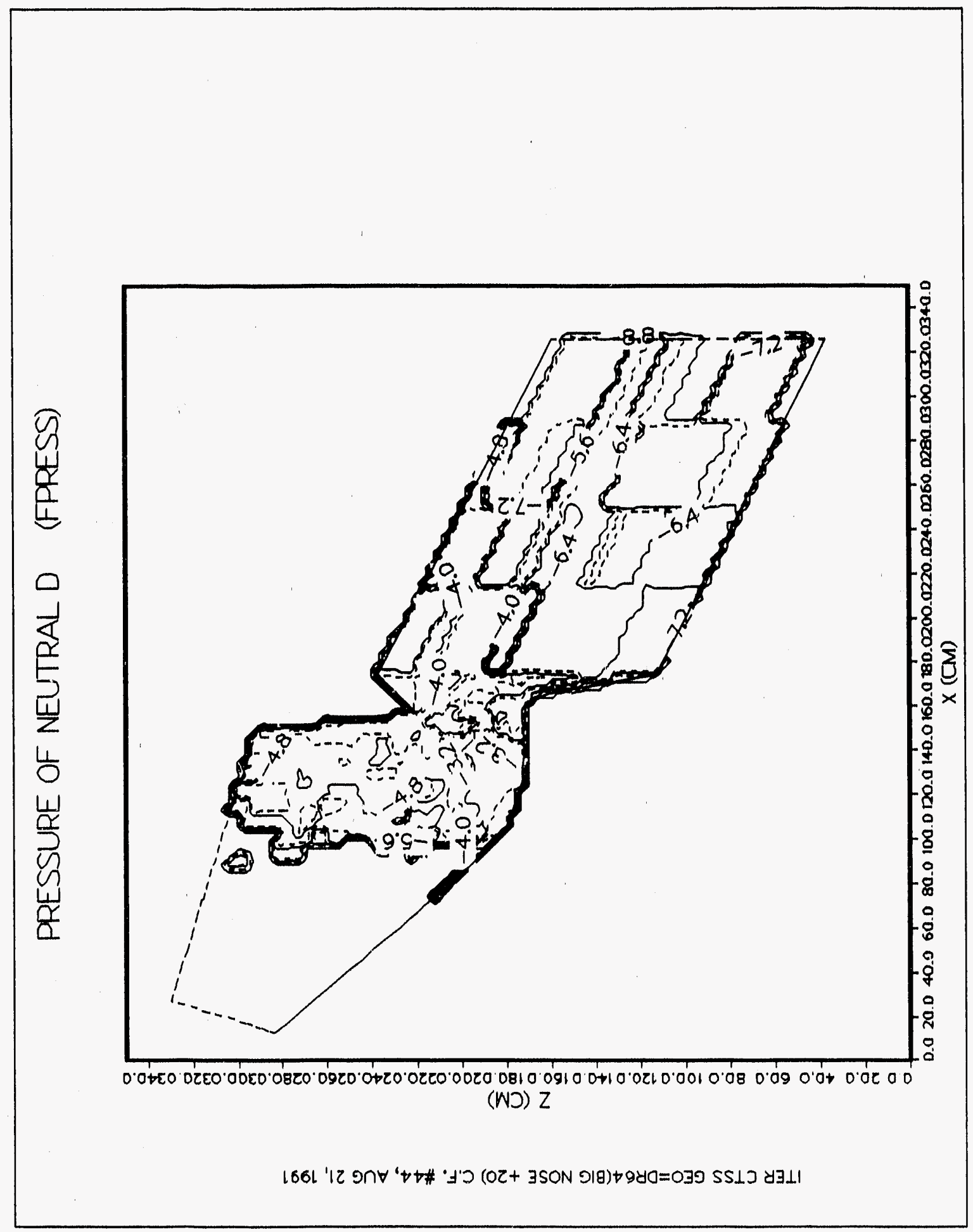




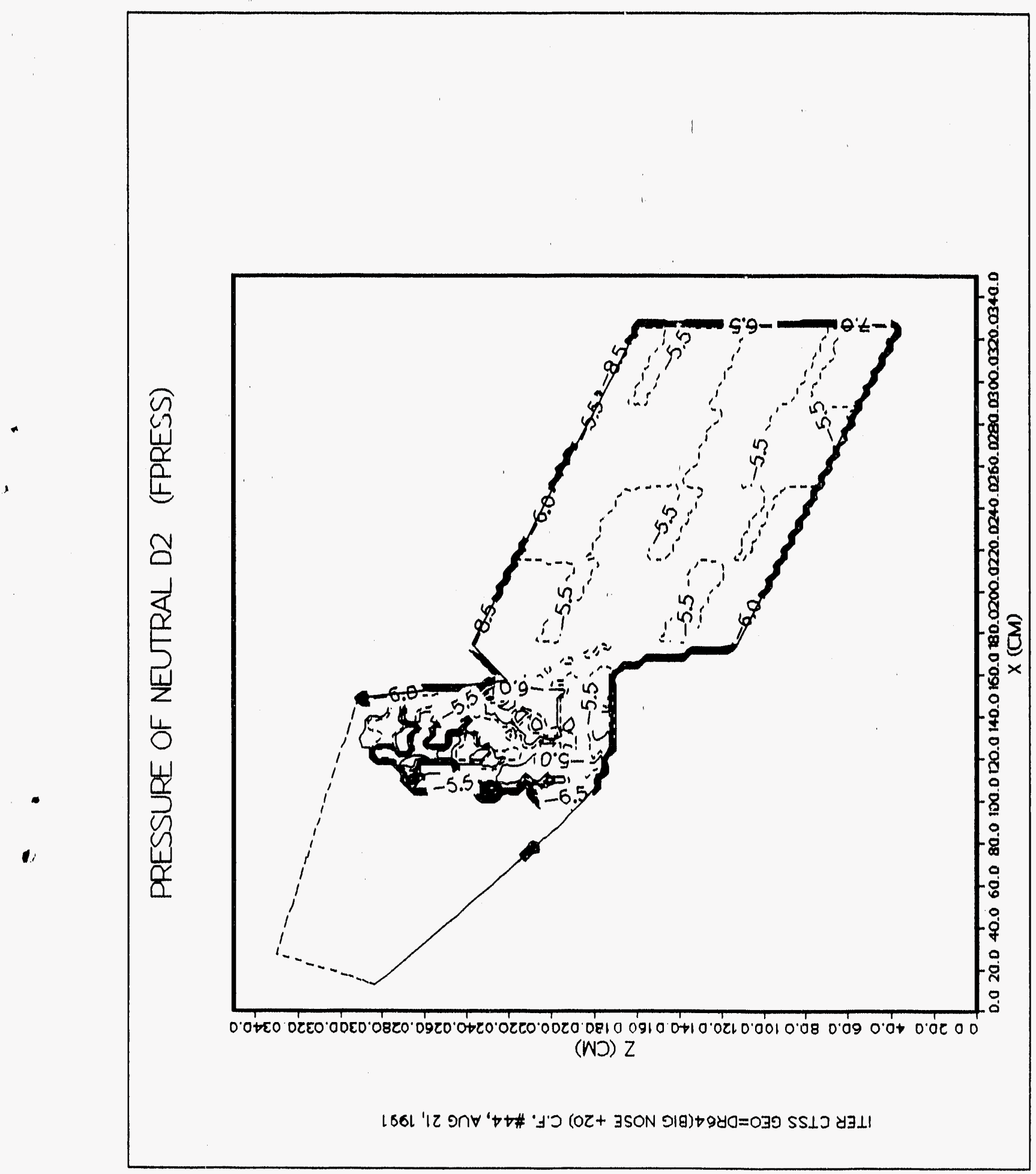




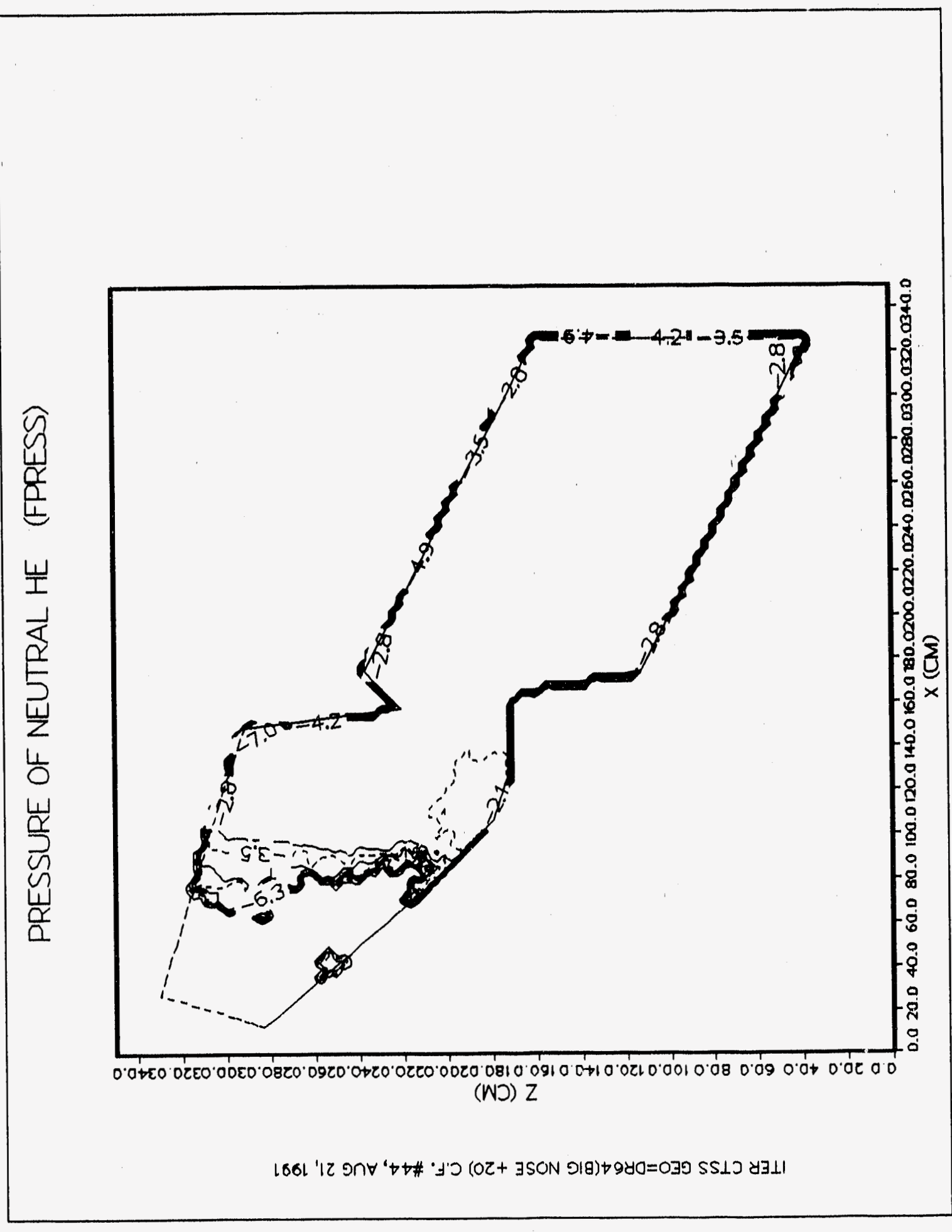


DATE

FILMED

$2 / 27 / 92$ 
